\title{
Odor modulates the temporal dynamics of fear memory consolidation
}

\author{
Stephanie L. Grella, Amanda H. Fortin, Olivia McKissick, Heloise Leblanc, \\ and Steve Ramirez
}

Psychological and Brain Sciences, Boston University, Boston, Massachusetts 02215, USA

\begin{abstract}
Systems consolidation (SC) theory proposes that recent, contextually rich memories are stored in the hippocampus (HPC). As these memories become remote, they are believed to rely more heavily on cortical structures within the prefrontal cortex (PFC), where they lose much of their contextual detail and become schematized. Odor is a particularly evocative cue for intense remote memory recall and despite these memories being remote, they are highly contextual. In instances such as posttraumatic stress disorder (PTSD), intense remote memory recall can occur years after trauma, which seemingly contradicts SC. We hypothesized that odor may shift the organization of salient or fearful memories such that when paired with an odor at the time of encoding, they are delayed in the de-contextualization process that occurs across time, and retrieval may still rely on the HPC, where memories are imbued with contextually rich information, even at remote time points. We investigated this by tagging odor- and non-odor-associated fear memories in male c57BL/6 mice and assessed recall and c-Fos expression in the dorsal CAl (dCAl) and prelimbic cortex (PL) 1 or 21 d later. In support of SC, our data showed that recent memories were more dCAl-dependent whereas remote memories were more PL-dependent. However, we also found that odor influenced this temporal dynamic, biasing the memory system from the PL to the dCAl when odor cues were present. Behaviorally, inhibiting the dCAl with activity-dependent DREADDs had no effect on recall at $1 \mathrm{~d}$ and unexpectedly caused an increase in freezing at $21 \mathrm{~d}$. Together, these findings demonstrate that odor can shift the organization of fear memories at the systems level.
\end{abstract}

Remembering personal experiences, or episodic memories, relies upon the integrity of the hippocampus (HPC) (Scoville and Milner 1957). When an episodic memory is formed, many of the contextual elements of the experience are encoded. The set of brain cells, or neuronal ensembles active during memory formation can be referred to as an engram (Semon 1921) and natural recall of an episodic memory involves reactivation of those engrams (Deng et al. 2013; Tonegawa et al. 2015; Holtmaat and Caroni 2016). Experiential recall can also be induced by artificial reactivation of engram cells using genetic tagging and optogenetic or chemogenetic stimulation.

New memories which are initially labile, gain stability and permanence through consolidation. Consolidation is a process of reorganization that occurs within the hours following the encoding of an experience at the synaptic level (local changes in connectivity), and gradually over years at the systems level (brain-wide changes in connectivity) (Frankland and Bontempi 2005). Some of the first evidence that led researchers to understand the fundamental necessity of the HPC in the early stages of memory formation and consolidation came from individuals with hippocampal damage who experienced anterograde amnesia or the inability to form new memories, as a result. These patients also showed temporally graded retrograde amnesia (sometimes called the Ribot gradient) (Ribot 1882) where the magnitude of hippocampal damage was correlated with the temporal gradient of amnesia. In these individuals, damage to the HPC was associated with deficits for recently acquired memories, however, more distant memories were still intact (Zola-Morgan and Squire 1986; Rempel-Clower et al. 1996; Kapur and Brooks 1999; Bayley et al. 2003; Kirwan

Corresponding author: dvsteve@bu.edu

Article is online at http://www.learnmem.org/cgi/doi/10.1101/lm.050690. 119. Freely available online through the Learning \& Memory Open Access option. et al. 2008). The opposite pattern was observed when cortical structures like the PFC sustained damage-remote memories were lost (retrograde amnesia), while recent memory was unaffected (Markowitsch et al. 1993; Mangels et al. 1996; Reed and Squire 1998; Murre et al. 2001; Bayley et al. 2003, 2005; Squire and Bayley 2007; Squire and Wixted 2011).

The theory of systems consolidation (SC) proposes a mechanism for these findings, arguing that as memories become older, or more remote, they become less HPC-dependent, and more dependent on the PFC (Ribot 1882; Squire 1992; Lechner et al. 1999; Frankland et al. 2004; Wiltgen et al. 2004; Frankland and Bontempi 2005; Nadel et al. 2007; Squire and Bayley 2007; Squire et al. 2015), a process that is thought to be mediated by postlearning spontaneous engram reactivation during sleep (Hebb 1949; Marr 1971; Skaggs and McNaughton 1996; Redish and Touretzky 1998; Mölle et al. 2006; de Sousa et al. 2019). As this transition occurs, it is hypothesized that memories lose many of their rich contextual details (Tse et al. 2007; Kitamura et al. 2017). In accordance with this, retrieval of a memory shortly after an experience involves reactivation of HPC engram cells whereas retrieval occurring later involves reactivation of PFC engram cells (Maviel et al. 2004; Wiltgen et al. 2004, 2010; Ross and Eichenbaum 2006; Gonzalez et al. 2013; Doron and Goshen 2018). However, several observations challenge this model, such as the qualitative observation that people often retrieve remote memories that are vivid and highly detailed (Bonnici et al. 2012). Likewise, several studies have shown that there is activity in both structures during both recent and remote memory recall (Piolino et al. 2004; Goshen et al. 2011; Bonnici et al. 2012; Bonaccorsi 
et al. 2013; Lux et al. 2016) and that damage to the HPC sometimes affects remote memory as well as recent memory (Shimizu et al. 2000; Debiec et al. 2002; Broadbent et al. 2006; Teixeira et al. 2006; Kirwan et al. 2008; Sutherland et al. 2008; Irish et al. 2010; Zelikowsky et al. 2012).

Multiple trace theory (MTT), an alternative to the standard model of SC, accounts for these findings arguing that irrespective of when they are acquired, vivid autobiographical memories always engage the HPC (Nadel and Moscovitch 1997; Nadel et al. 2000; Rosenbaum et al. 2001; Gilboa et al. 2004; Meeter and Murre 2004; Moscovitch et al. 2005; Rekkas and Constable 2005). Here, remote memories retain rich contextual detail (Suzuki and Naya 2011) as long as the trace in the HPC is dominant at the time of retrieval. However, there is evidence to suggest that engrams are, in fact, encoded in parallel across both brain regions (Kirchhoff et al. 2000; Blumenfeld and Ranganath 2007; Qin et al. 2007; Goshen et al. 2011; Lesburgueres et al. 2011; Tayler et al. 2013) and that the architecture of memory traces formed during encoding are sparse but distributed (Rao-Ruiz et al. 2019; Roy et al. 2019) supporting a third, more flexible model: competitive trace theory (CTT). CTT suggests that multiple traces exist (e.g., HPC and PFC) and that memories do become more schematized or decontextualized over time and more reliant on neocortical storage but that the HPC can function to recontextualize memories, at any time, even at remote time points (Yassa and Reagh 2013).

The temporal separation between recent and remote memories is ambiguous (Doron and Goshen 2018). In the case of posttraumatic stress disorder (PTSD) these lines may be even more blurred given that sometimes trauma-related memories can be recalled with vivid detail many years after the traumatic event (Wagenaar and Groeneweg 1990; Schelach and Nachson 2001; Vermetten and Bremner 2003; Rubin et al. 2004, 2011; Berntsen and Thomsen 2005; Janssen et al. 2011; Fernández-Lansac and Crespo 2017) which may be related to the highly arousing nature of these memories (Kensinger and Schacter 2008; Liu and McNally 2017). However, there are conflicting views regarding how emotion modulates memory in general (Rubin et al. 2008; Fernández-Lansac and Crespo 2017). More specifically, odor seems to be a particularly powerful contextual cue that can evoke this experience long after memories are stabilized (Vermetten and Bremner 2003; Arshamian et al. 2013). Odors can be potent triggers of memories, (Daniels and Vermetten 2016) and as such, we believe that if they are present during encoding, they can shift the organization of arousing memories at the systems level, to a state of HPC-dependent processing.

To analyze the modulatory role of odor in the temporal dynamics of memory consolidation, we designed an experiment to visualize sets of engram cells at recent and remote time points. We hypothesized that fear-related memories would become more PFC-dependent and less HPC-dependent with the passage of time. Second, we hypothesized that if we fear-conditioned animals with an odor present, that this contextual element would shift the temporal organization of that memory such that it would be less reliant on the PFC, and more so on the HPC even at remote time points. Theoretically, if our data supports SC then inhibiting activity in the HPC should only affect recent and not remote memory retrieval. However, if odor can shift this organization, then inactivation of HPC engram cells related to an odor-associated fear memory will also affect retrieval at the remote time point. If our data support MTT or CTT, then we should also see an impairment at both time points.

Briefly, we utilized chemogenetic and virus-based strategies to locate and tag cells during the formation of a contextual fear memory in c57BL/6 wild-type mice in a doxycycline (DOX)-regulated manner. The viruses used comprise an inducible and activitydependent system in order to control which cells are tagged and later inhibited. It is inducible because it is controlled by DOX (a derivative of tetracycline), which when present in the animal's diet, prevents expression of the inhibitory hM4Di DREADD and the associated fluorescent reporter eYFP, and when absent allows for their expression. The system is activity-dependent because the expression of these proteins is driven by the immediate early gene c-Fos promoter, often used as a neuronal marker of activity. Mice were taken off DOX and then fear-conditioned to tag the cells involved. Mice were placed back on DOX and then tested for memory recall either 1 or $21 \mathrm{~d}$ later and half the mice were exposed to almond extract odor during conditioning and recall. Upon recall, mice were given $\mathrm{CNO}$ to inhibit the cells active during fear conditioning. We measured freezing levels across sessions and at the end of the experiment we quantified $c$-Fos activity in the dorsal CA1 (dCA1) of the HPC as well as the prelimbic cortex (PL) of the PFC.

\section{Results}

Viral transduction and activity-dependent engram labeling Viral transduction was localized to target regions (PL and dCA1) (Fig. 1A-C). Mis-targeted animals were excluded from data analysis. There were no group differences in the proportion of DAPI-labeled cells within the PL (Fig. 1E,G left) and dCA1 (Fig. $1 D, F$ left). Likewise, there were no group differences in the percentage of cells that were labeled with eYFP during fear conditioning in the PL (Fig. 1E,G right) and dCA1 (Fig. 1D,F right).

\section{Inhibiting the CAl with DREADDs did not impair fear memory recall}

To assess whether odor modulates SC of a fear memory we used a four-shock contextual fear conditioning protocol. Animals were initially placed in the context without shock for $198 \mathrm{sec}$. Figure 2B,G shows that during this PreShock period the mice exhibited very low levels of freezing which was significantly elevated during the PostShock period $F_{(1,40)}=233.179, P=0.000$ [main effect (ME) of TIME: three-way RM ANOVA] and increased with each successive shock $F_{(3,120)}=105.876, P=0.000$ (ME of SHOCK: three-way RM ANOVA; Fig. 2C,H). ODOR did not have an effect on freezing during fear-conditioning (Fig. 2B,G). Comparable levels of freezing were observed in hM4Di-Saline animals (PostShock $43.43 \pm$ $3.81 \%$. Mice were then returned to the fear-conditioning chamber either $1 \mathrm{~d}$ (RECENT) or $21 \mathrm{~d}$ (REMOTE) later to assess fear memory recall. In animals that were tested for memory recall $1 \mathrm{~d}$ after fearconditioning (RECENT), inhibiting cell bodies in the dCA1 transfected with DREADDs did not have any behavioral consequences (Fig. 2D,E) as there were no group differences or interactions in freezing levels [between-subject effects of ODOR and VIRUS: $n s$; two-way ANOVA]. The Recall session lasted $5 \mathrm{~min}$ and all animals froze significantly less in the first minute compared to the rest of the session $F_{(1,95)}=5.127, P<0.001$ (ME of TIME: three-way RM ANOVA; Fig. 2E). Animals in the hM4Di-Saline group showed similar levels of freezing to the other groups (Total $=43.66 \pm 10.67 \%$ ). In mice tested for recall at $21 \mathrm{~d}$ (REMOTE), there was a decline in freezing in controls (NO ODOR, eYFP) and no difference between these animals and eYFP mice that received ODOR (Fig. 2I). Surprisingly, both ODOR and NO ODOR mice that received DREADDs demonstrated modestly higher levels of freezing (Fig. 2I) although this did not reach a level of statistical significance $F_{(1,21)}=4.133, \quad P=0.055$ (ME of VIRUS: two-way ANOVA). Similarly, when the session was divided into 1-min bins, all mice froze significantly less in the first minute compared to the rest of the session $F_{(1,105)}=4.422, P=0.002$ (ME of TIME: three-way RM ANOVA; Fig. 2J) and DREADDs animals froze significantly 


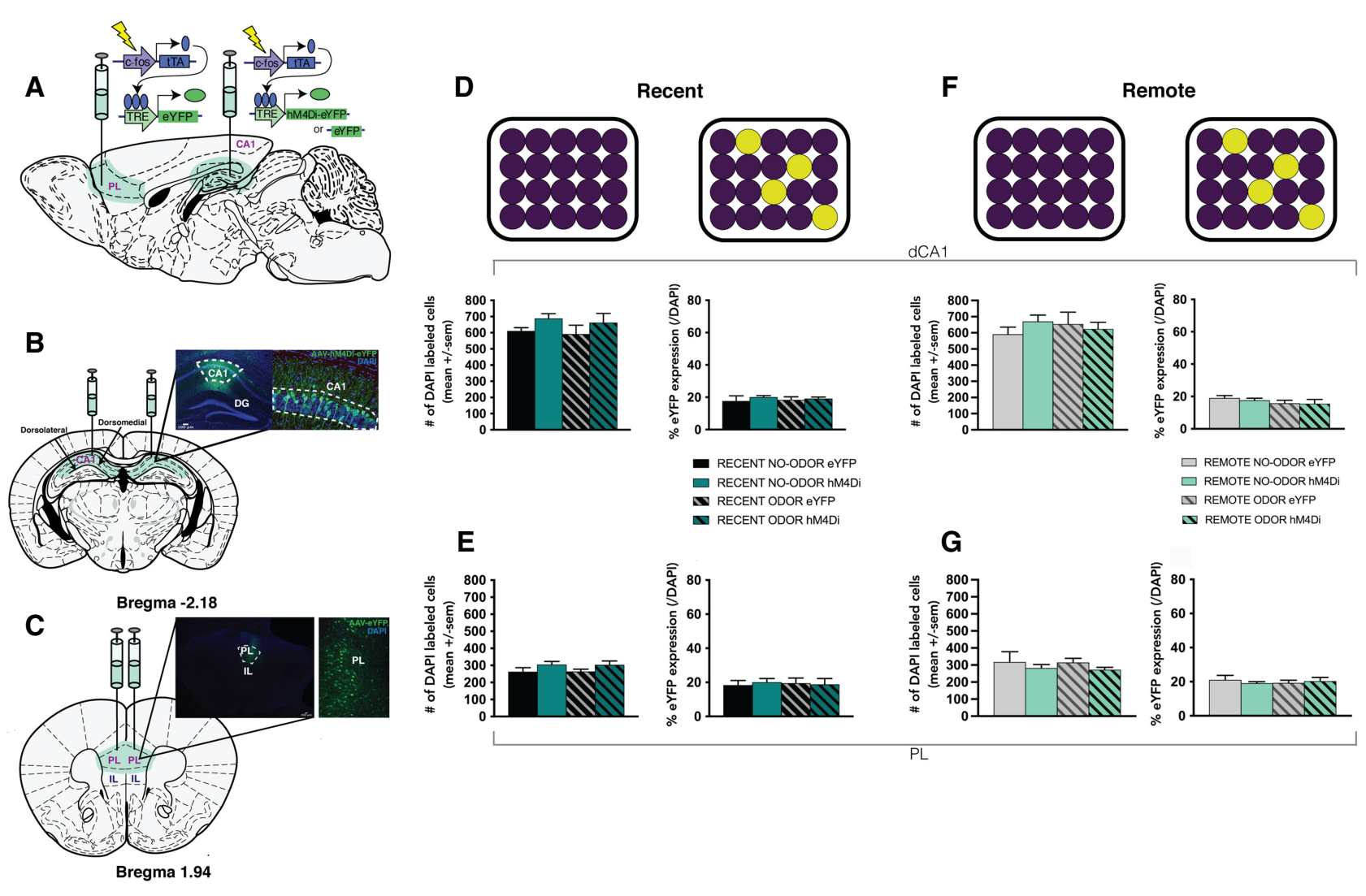

Figure 1. Viral transduction and activity-dependent engram labeling. $(A-C)$ Viral transduction was localized to target regions: Prelimbic Cortex (PL) and dorsal CA1 (dCA1). In the PL, all mice were injected with AAV9-cFos-tTa-TRE-eYFP and in the dCA1 with either AAV9-cFos-tTa-TRE-hM4Di-eYFP (inhibitory DREADDs) or AAV9-cFos-tTa-TRE-eYFP. The proportion of DAPI-labeled cells (left) and eYFP+ cells (right) labeled during fear conditioning, when fear memory recall was tested after $1 \mathrm{~d}$ (Recent condition), within the dCA1 (D) and the PL (E). The proportion of DAPI-labeled cells (left) and eYFP+ cells (right) labeled during fear conditioning, when fear memory recall was tested after $21 \mathrm{~d}$ (Remote condition), within the dCA1 ( $F)$ and the PL $(G)$. Groups: RECENT-NO-ODOR-eYFP $(n=7)$, RECENT-NO-ODOR-hM4Di $(n=5)$, RECENT-ODOR-eYFP $(n=7)$, RECENT-ODOR-hM4Di ( $n=5)$, REMOTE-NO-ODOR-eYFP $(n=8)$, REMOTE-NO-ODOR-hM4Di $(n=5)$, REMOTE-ODOR-eYFP $(n=7)$, REMOTE-ODOR-hM4Di $(n=5)$.

more $F_{(1,105)}=14.742, P<0.001$ (ME of VIRUS: three-way RM ANOVA; Fig. 2J).

\section{Odor modulates the temporal characteristics of systems consolidation}

c-Fos expression during fear memory recall

Ninety minutes after the Recall session all animals were perfused so that $c$-Fos levels in the dCA1 and PL could be quantified. Given that inhibitory hM4Di DREADDs should theoretically silence neurons, and thus $c$-Fos expression, our predictions involving $c$-Fos expression are with respect to eYFP animals only. In line with SC theory, we hypothesized that REMOTE compared to RECENT fear memory recall would be less HPC-dependent evinced by lower $c$-Fos levels in the dCA 1 at $21 \mathrm{~d}$ compared to $1 \mathrm{~d}$ and that the reverse profile would be observed in the PL. We also hypothesized that ODOR would bias this effect such that a fear memory associated with an odor would continue to be HPC-dependent even at the REMOTE time point.

\section{Dorsal hippocampus: $d C A 1$}

Figure 3E,I shows that in the dCA1, odor did not change the level of $c$-Fos expression at the RECENT time point as both ODOR and NO ODOR animals demonstrated similar $c$-Fos levels. In agreement with SC, we found that in eYFP animals, $c$-Fos levels declined at the REMOTE time point and as we predicted, specifically in the NO ODOR group and not in the ODOR group $\mathrm{F}_{(1,32)}=4.173$, $P=0.049 \quad$ (ODOR $\times$ VIRUS interaction: three-way ANOVA). Post-hoc analyses showed a significant difference between the NO ODOR eYFP groups at 1 and $21 \mathrm{~d} t_{(11)}=3.017, P=0.012$ and between eYFP ODOR and no ODOR groups at $21 \mathrm{~d} t_{(11)}=2.655, P=$ 0.022 . Figure $3 B, E$ shows that in mice conditioned with ODOR, immunoreactivity of $c$-Fos remained elevated even at the REMOTE time point $F_{(1,18)}=5.656, P=0.029$ (ODOR $\times$ VIRUS interaction: two-way ANOVA) suggesting that odor can modulate the temporal characteristics of memory consolidation in that it can delay, or even potentially abolish the redistribution of fear memories from the HPC to the PFC.

At the RECENT time point there were no differences between the ODOR and NO ODOR groups $F_{(1,14)}=0.220, P=0.646$ (twoway ANOVA). However, unexpectedly c-Fos levels were higher in DREADDs animals compared to eYFP animals $F_{(1,32)}=15.665$, $P<0.001$ (ME of VIRUS: three-way ANOVA) and this was true at 1 $\mathrm{d} F_{(1,18)}=11.166, P=0.005$ (ME of VIRUS: two-way ANOVA) and $21 \mathrm{~d} F_{(1,18)}=6.205, P=0.023$ (ME of VIRUS: two-way ANOVA) (Fig. $3 \mathrm{E})$. This effect was even more pronounced in the NO ODOR condition at $1 \mathrm{~d} q_{(2)}=3.974, P=0.014$ and $21 \mathrm{~d} q_{(2)}=5.125, P=0.002$.

\section{Prefrontal cortex: PL}

In Figure 3G,I, we found additional support for SC in the PL where c-Fos levels were significantly elevated at the REMOTE compared to 
A
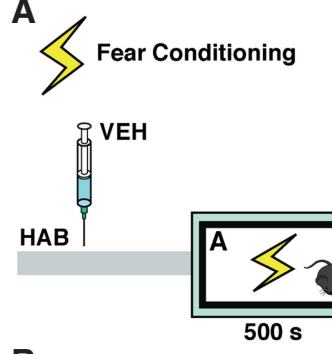

B

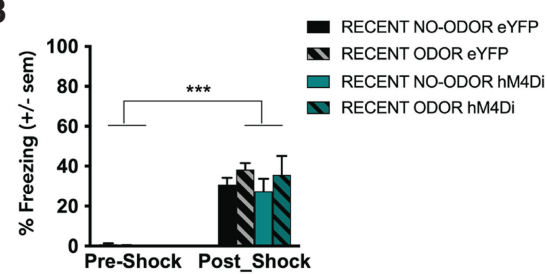

C
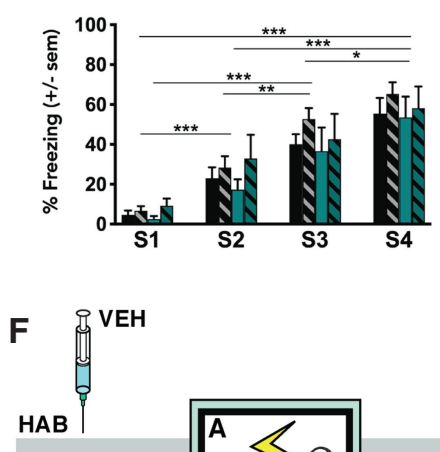

G

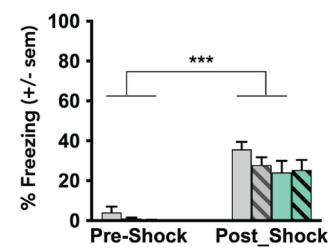

H
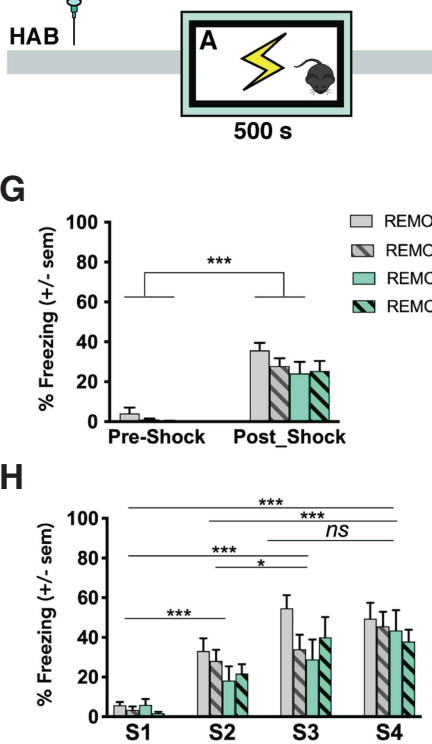

$500 \mathrm{~s}$
CNO/Vehicle Injections

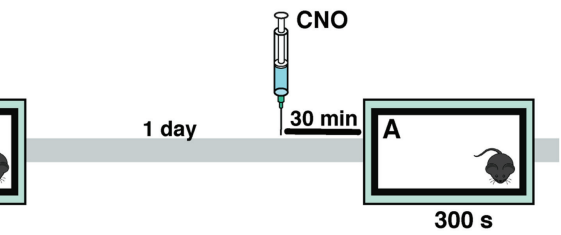

D

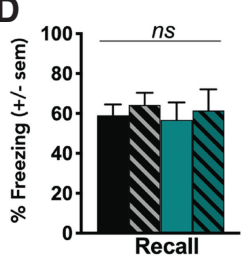

E

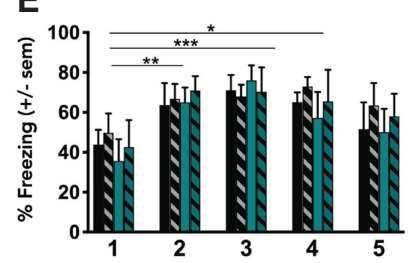

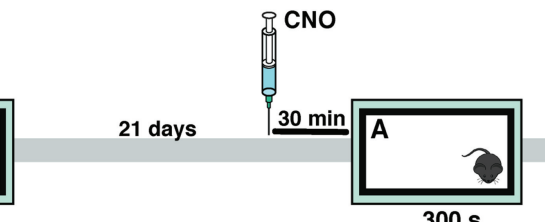

$300 \mathrm{~s}$
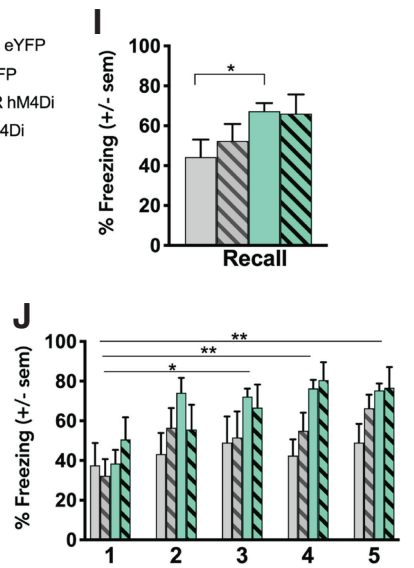

Figure 2. Inhibiting the CA1 with DREADDs did not impair fear memory recall. To assess whether odor modulates SC of a fear memory we used a four-shock contextual fear conditioning (FC) protocol where animals were tested either in the presence of odor or no odor and tested for recall $1 \mathrm{~d}$ (Recent) or $21 \mathrm{~d}$ (Remote) later. (A) Timeline of our behavioral experiment for animals tested at $1 \mathrm{~d}$. (B) Animals were initially placed in context A without shock for 198s (PreShock) where they exhibited very low levels of freezing which was significantly elevated during the PostShock period $(C)$ and increased with each successive shock. $(D)$ Mice were then returned to the FC context $1 \mathrm{~d}$ later for a 5 min fear memory recall test. $(E)$ Data shown across 1 min bins. Inhibiting cell bodies in the dCA1 with DREADDs did not have any behavioral consequences. ( $F$ ) Timeline of our behavioral experiment for animals tested at 21 d. (G) Animals were initially placed in context A without shock for 198s (PreShock) where they exhibited very low levels of freezing which was significantly elevated during the PostShock period $(H)$ and increased with each successive shock. $(I)$ Mice were then returned to the FC context $21 \mathrm{~d}$ later for a 5 min fear memory recall test. ( /) Data shown across 1 min bins. Inhibiting cell bodies in the dCA1 with DREADDs caused an increase in freezing in both odor and no odor conditions. $\left.{ }^{*}\right) P<0.05$, $\left.{ }^{* *}\right) P<$ $0.01,\left({ }^{* * *}\right) P<0.001$. the RECENT time point $F_{(1,33)}=19.466, P$ $<0.001$ (ME of RECALL: three-way ANOVA). As in the dCA1, c-Fos levels in the PL were higher in DREADDs animals compared to eYFP animals at $1 \mathrm{~d}$ but not at $21 \mathrm{~d} F_{(1,16)}=11.585, P=0.004(\mathrm{ME}$ of VIRUS: two-way ANOVA).

At the REMOTE time point, c-Fos levels were equally elevated for all groups with no effect of ODOR (Fig. 3G,I). However, at the RECENT time point, $c$-Fos levels were elevated in DREADDs animals but only in the NO ODOR group $F_{(1,16)}=$ $10.318, P=0.005$ (ME of ODOR: two-way ANOVA, Fig. 3G). Post-hoc tests showed a significant difference between the NO ODOR DREADDs groups and the NO ODOR eYFP group $q_{(2)}=5.360, P=0.002$, and the ODOR DREADDs group $q_{(2)}=$ 4.718, $P=0.004$ at the RECENT time point. This suggests that inhibiting or perturbing the dCA1 with DREADDs during fear memory recall after $1 \mathrm{~d}$ results in increased activity in the PL unless an odor is present. This further supports our hypothesis that odor can shift the temporal organization of fear memories to be less dependent on the PFC and more dependent on the HPC.

Chemogenetic inhibition of engram cells activates c-Fos in neighboring nonengram cells

\section{Fear memory encoding and recall overlaps}

We next examined the overlap between labeled fear engram neurons (eYFP) and cells active during the recall session (c-Fos). We hypothesized that in the dCA1, in NO ODOR animals, there would be higher overlap at the RECENT versus REMOTE time point whereas in the ODOR animals we expected to see high overlap at both time points. We hypothesized that the opposite would be true in the PL with higher overlap at the REMOTE versus RECENT time point and that ODOR would decrease this overlap. Again, our predictions involving overlap are with respect to eYFP animals only taking into consideration that we used inhibitory DREADDs to silence neurons. However, given that DREADDs in this experiment increased $c$-Fos expression, we also looked at overlap in the DREADDs groups to assess whether we could glean insight into the increased levels of freezing seen at the REMOTE time point in these animals.

\section{Dorsal hippocampus: $d C A 1$}

In the dCA1, exhibited by a significant ODOR $\times$ RECALL interaction $F_{(1,19)}=$ 5.486, $P=0.03$ (two-way ANOVA), in 
A
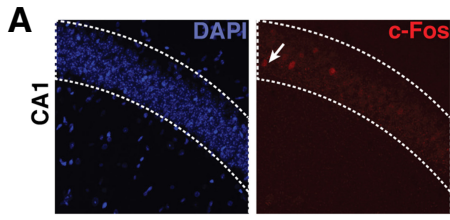

B

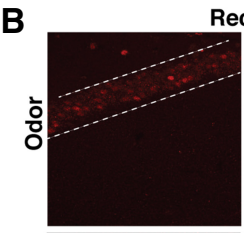

Recent
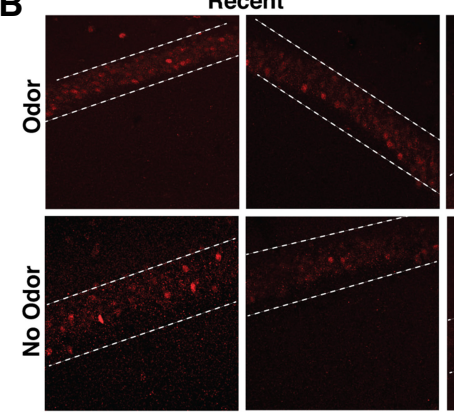

C
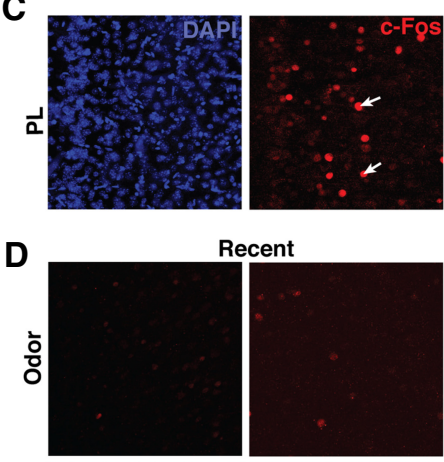

Recent
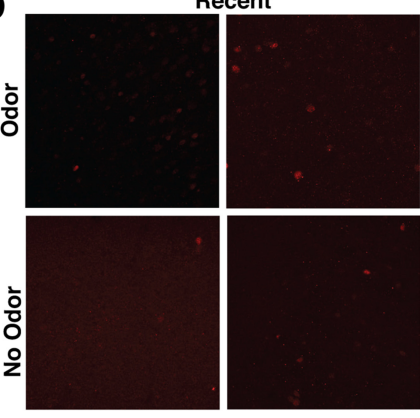
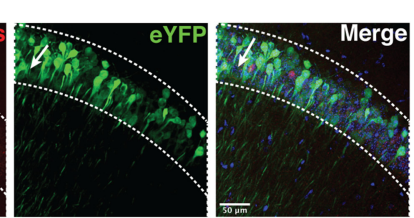

Remote
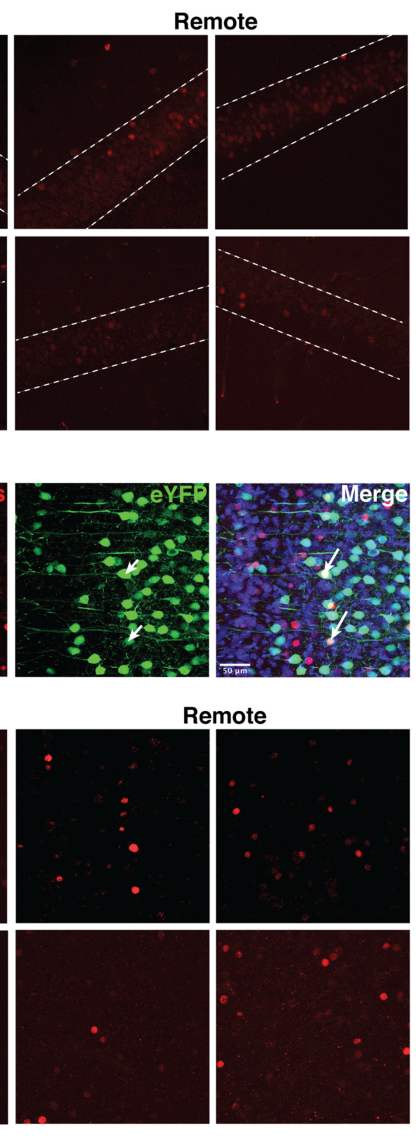

Remote

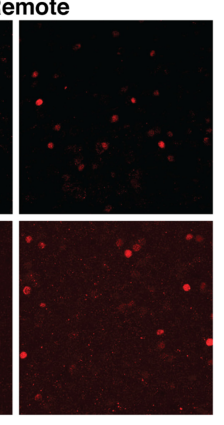

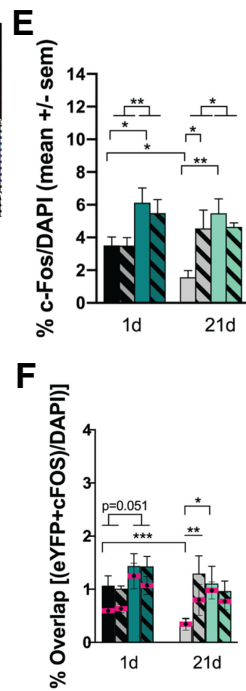
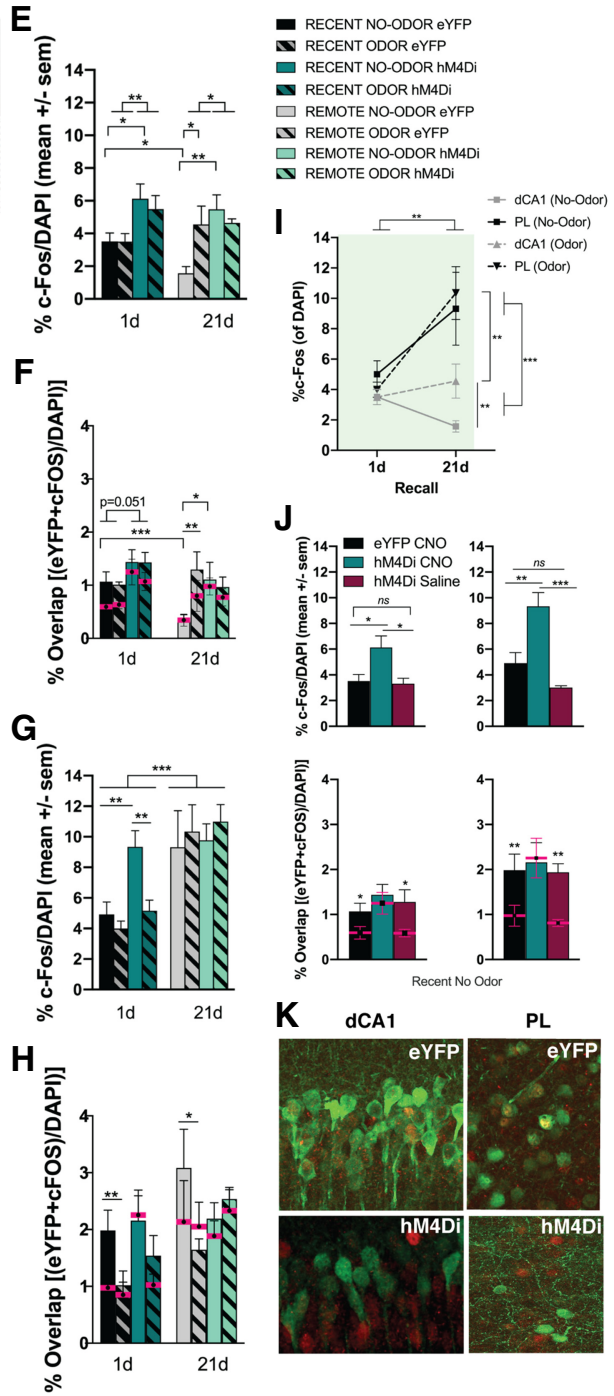
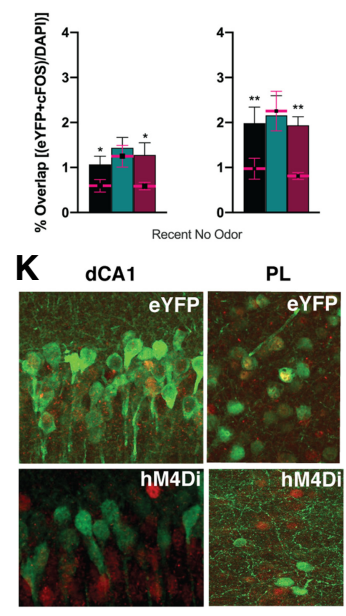

Figure 3. Odor modulates the temporal characteristics of SC. For both recall sessions ( 1 and $21 \mathrm{~d})$, the total number of DAPI positive (+), eYFP+ (cells tagged during fear conditioning), c-Fos+ (cells active during fear memory recall), and eYFP+ and c-Fos+ (cells active in both behavioral epochs) neurons in the $(A) \mathrm{dCA} 1$ and $(C)$ PL were quantified. (B) In eYFP animals, in dCA1 odor did not change $c$-Fos expression at $1 \mathrm{~d}$ as predicted, $c$-Fos levels declined at $21 \mathrm{~d}$ in the no odor group but remained elevated in the odor group. (D) In eYFP animals, in the PL, c-Fos levels were significantly higher at $21 \mathrm{~d}$ compared to 1 d. Two images per condition are provided. $(E)$ The $\%$ of $c$-Fos immunoreactive neurons was defined as a proportion of total DAPI labeled cells. In dCA1, there was a significant difference between no odor eYFP groups at $1 \mathrm{~d}$ and $21 \mathrm{~d}$ and between eYFP odor and no odor groups at $21 \mathrm{~d}$. Unexpectedly, c-Fos levels were higher in DREADDs animals compared to eYFP animals. $(F)$ Overlaps were considered the proportion of DAPI-labeled cells that were both c-Fos+ and eYFP+. Chance overlap was calculated as the $\%$ of eYFP+ neurons $\times$ the $\%$ of $c$-Fos + neurons over the total number of DAPI neurons (pink line). Overlaps followed the same pattern as c-Fos. (G) In the PL, c-Fos levels were significantly elevated at $21 \mathrm{~d}$ compared to $1 \mathrm{~d}$ with the exception of the no odor group at $1 \mathrm{~d}$. As in dCA1, c-Fos was also higher in DREADDs animals compared to eYFP animals at $1 \mathrm{~d}$ but not $21 \mathrm{~d}$. (H) Odor decreased overlaps to chance. $(I)$ In eYFP animals, contextual fear memories become more reliant on the PL with time irrespective of odor. Conversely, they become less reliant on the dCA1 with time, if no odor is present. However, if odor is present during encoding and again upon retrieval, these memories continue to engage the dCA1. Inhibiting dCA1 with CNO using DOX-regulated, c-Fos promoter driven DREADDs introduced using an adeno-associated virus to tag fear engram cells produced an increase in $c$-Fos levels. $(J)$ In the no odor groups at 1d, DREADDs + CNO mice showed greater numbers of $c$-Fos+ cells, compared to DREADDs + Saline or eYFP + CNO mice in both the dcA1 (top left) and the PL (top right). These increases in c-Fos were predominantly seen in nonengram cells. When we view the proportion of double-labeled cells, they occur to a significantly higher degree that chance in the eYFP-CNO and hM4Di-Saline mice, but not for hM4Di-CNO animals where c-Fos is increased in nonengram cell populations in the dCA1 (bottom left) and the PL (bottom right). Pictured in (K) dCA1 (left) and the PL (right). $\left(^{*}\right) P<0.05,\left(^{* *}\right) P<0.01,\left(^{* * *}\right) P<0.001$.

accordance with our hypothesis, we found that within the NO ODOR eYFP condition there was a higher degree of overlap between the cells active during fear-conditioning and recall at the RECENT time point compared to the REMOTE time point $t_{(11)}=$ 3.404, $P=0.006$. This is in contrast to the ODOR eYFP condition where overlap was elevated at both time points (Fig. 3F). A Mann-Whitney test indicated that overlap was greater in the
ODOR group $(\mathrm{Mdn}=1.057)$ compared to the NO ODOR group $(\mathrm{Mdn}=0.262)$ at the REMOTE time point $(\mathrm{U}=3, P=0.008)$. Moreover, both ODOR and NO ODOR eYFP groups had higher than chance levels of overlap at the RECENT time point $q_{(2)}=$ 4.03, $P=0.008$ as well the ODOR eYFP group at the REMOTE time point $q_{(2)}=6.417, P<0.001$ ) (Fig. 3F). For animals that received DREADDs, there were no differences in overlap across 
time points, and while the percentage of overlap was similar to eYFP animals, contrastingly, the percentage of overlap did not differ from chance as it did in the eYFP mice (Fig. 3F) except for the ODOR group at the RECENT time point $q_{(2)}=3.861, P=0.01$. In the NO ODOR animals, overlap here was greater in the DREADDs group compared to the eYFP group at the REMOTE time point $q_{(2)}=3.186, P=0.037$. This pattern suggests that $c$-Fos levels were increased in neighboring nonengram cells (Fig. $3 \mathrm{~K}$ left).

\section{Prefrontal cortex: $P L$}

In the PL, a three-way ANOVA revealed a significant ME of RECALL $F_{(1,33)}=6.808, P=0.014$ and a significant ME of ODOR $F_{(1,33)}=$ 6.787, $P=0.014$ as well as a significant ODOR $\times$ VIRUS interaction $F_{(1,33)}=4.382, P=0.044$. Specifically within the eYFP animals using a two-way ANOVA, there was a significant ME of RECALL $F_{(1,19)}=$ 4.697, $P=0.043$ and a significant ME of ODOR $F_{(1,19)}=9.874, P=$ 0.005 but no interaction signaling that ODOR decreased overlap to chance (only eYFP NO ODOR groups differed from chance: RECENT $-q_{(2)}=5.211, P<0.001$; REMOTE $-q_{(2)}=4.499, P=0.003$, all other groups $n s$ ) at both time points (Fig. $3 \mathrm{H}$ ). This suggests that odor-associated memories are not processed in the PL or at least suggests that this is the case when recall occurs in the presence of the same odor that was present at the time of encoding. Post-hoc analyses supports that this is the case at the RECENT time point $q_{(2)}$ $=3.15, P=0.033$ specifically for eYFP animals $q_{(2)}=4.414, P=0.007$. However, due to high levels of variability in the NO ODOR group this effect was not observed at the REMOTE time point $q_{(2)}=$ 2.08, $P=0.151$ (Fig. 3H). A two-way ANOVA across ODOR and VIRUS at the REMOTE time point revealed a significant difference between the ODOR and NO ODOR groups in the eYFP condition $q_{(2)}=3.937, P=0.013$. It remains unknown whether overlap would still be low if encoding had been carried out in the presence of an odor as was the case in the current experiment, but the recall test had been conducted in the absence of odor.

Given that $c$-Fos levels were higher in the dCA1 in DREADDs animals compared to eYFP animals $t_{(14)}=-4.112, P=0.001$ (Fig. 3E) but that overlap was higher in the eYFP animals compared to the DREADDs animals at the RECENT time point $F_{(1,14)}=4.539, P=$ 0.051, two-way ANOVA) and the REMOTE time point $F_{(1,18)}=$ 4.563, $P=0.047$ (ODOR $\times$ VIRUS interaction, two-way ANOVA), this suggests that in the dCA1, DREADDs increased $c$-Fos and not necessarily in fear memory neuronal ensembles (Fig. 3K) and may be primarily increasing activity in neighboring neurons in a compensatory manner. We ran an additional control experiment without odor at the RECENT time point. We included a group (hM4Di-Saline) that was injected with the hM4Di virus in the dCA1 (as well as the eYFP virus in the PL), however, these animals received saline instead of $\mathrm{CNO}$. We compared $c$-Fos levels in these animals to mice that were given $\mathrm{CNO}$ as well as injected with the hM4Di virus (hM4Di-CNO) or the eYFP virus (eYFP-CNO), in the dCA1 (as well as the eYFP virus in the PL). Saline injections resulted in comparable expression of $c$-Fos in the dCA1 to eYFP animals $\left(F_{(2,13)}=5.753, P=0.019\right.$, one-way ANOVA) (Fig. 3J, top left). When we look at overlaps compared to chance we see that the increases in c-Fos occur within dCA1 engram cells for the eYFP-CNO $\left(t_{(3)}=3.910, P=0.011\right)$ and hM4Di-Saline animals $\left(t_{(3)}\right.$ $=-3.535, P=0.039)$, but not for hM4Di-CNO animals where c-Fos is increased in nonengram cell populations (Fig. 3J, bottom left) suggesting that chemogenetically silencing the neurons involved in fear memory encoding during recall $1 \mathrm{~d}$ later can result in increased $c$-Fos activity in nonengram hippocampal cells.

Interestingly, c-Fos levels were also increased in the PL in DREADDs animals, with the exception of the ODOR group at the RECENT time point (Fig. 3G). However, overlap was only elevated above chance for the NO ODOR groups at both RECENT and
REMOTE time points suggesting that even in the PL, DREADDs seem to be increasing c-Fos in a compensatory manner following inhibition of dCA1 engram cells, and not in PL engram cells (Fig. 3K). Moreover, when we looked at c-Fos levels in the PL in the control animals that had received saline instead of CNO, we found that they were also significantly lower than hM4Di-CNO animals demonstrating that inhibiting fear memory engram cells can cause an increase in activity in the PL $\left(F_{(2,13)}=4.84, P=\right.$ 0.031 , one-way ANOVA) (Fig. 3J, top right). When we look at overlaps compared to chance we see that the increases $c$-Fos occur within PL engram cells for the eYFP-CNO $\left(t_{(5)}=-6.263, P=0.002\right)$ and hM4Di-Saline animals $\left(t_{(3)}=-7.903, P=0.004\right)$, but not for hM4Di-CNO animals, where $c$-Fos is increased in nonengram cell populations (Fig. 3J, bottom right).

\section{Freezing was positively correlated with c-Fos expression and overlap in the dCAl and negatively correlated with c-Fos expression in the PL in controls}

We ran bivariate correlational analyses between freezing levels during the recall session and $c$-Fos expression as well as overlap in the dCA1 and in the PL. In NO ODOR eYFP animals we found that freezing was correlated with $c$-Fos $(r=0.729, n=11, P=0.011$, twotailed) and overlap ( $r=0.612, n=11, P=0.046$, two-tailed $)$ in the dCA1 (Fig. 4A,B) and negatively correlated with $c$-Fos in the PL ( $r=-0.647, n=9, P=0.032$, two-tailed) (Fig. 4C,D). When this was parsed across time, we saw no significant correlations. These animals showed a decrease in freezing across time and also a decrease in $c$-Fos levels in the dCA1 as well as an increase in c-Fos in the PL. In NO ODOR DREADDs animals, freezing during recall did not correlate with $c$-Fos or overlap in either brain region. In ODOR animals, we saw no significant correlations in eYFP or DREADDs animals and when we looked specifically at the groups that demonstrated increased freezing at the REMOTE time point, their freezing levels were not correlated with $c$-Fos or overlap in either the dCA1 or the PL. This suggests that there is a dissociation between these measures and freezing as a behavioral output, specifically in animals that received DREADDs and therefore, the increases in $c$-Fos observed in this condition are not likely related to the increased freezing observed at the REMOTE time point. However, it is possible that there was a ceiling effect on freezing reached here and these cells which are now c-Fos+ due to DREADD inhibition are conceivably contributing to freezing.

\section{Discussion}

As the French author Marcel Proust described long ago (Proust 1927), referenced in his work $A$ la Recherche du Temps Perdu which translates to In Search of Lost Time- "Yet a single scent already breathed long ago, may once again both be in the present and the past, be real without being present." Sensory experiences like olfaction and gustation have the ability to produce the evocation of vivid autobiographical memories of the distant past (Toffolo et al. 2012; Zucco et al. 2012; Daniels and Vermetten 2016; Glachet and El Haj 2019). This spontaneous process which we have all experienced at one time or another is often referred to as the Proust Phenomenon. Few studies have tried to unravel this phenomenon systematically. For most, this reverie can be a pleasant trip through time but for individuals with PTSD, odors can serve as triggers for extremely aversive experiences (Toffolo et al. 2012). The vivid nature of these experiences can make them all the more painful.

In this study, we sought to determine whether odor as a contextual cue, associated with a fear-related memory, could shift the temporal dynamics of the consolidation of that memory at the 
A
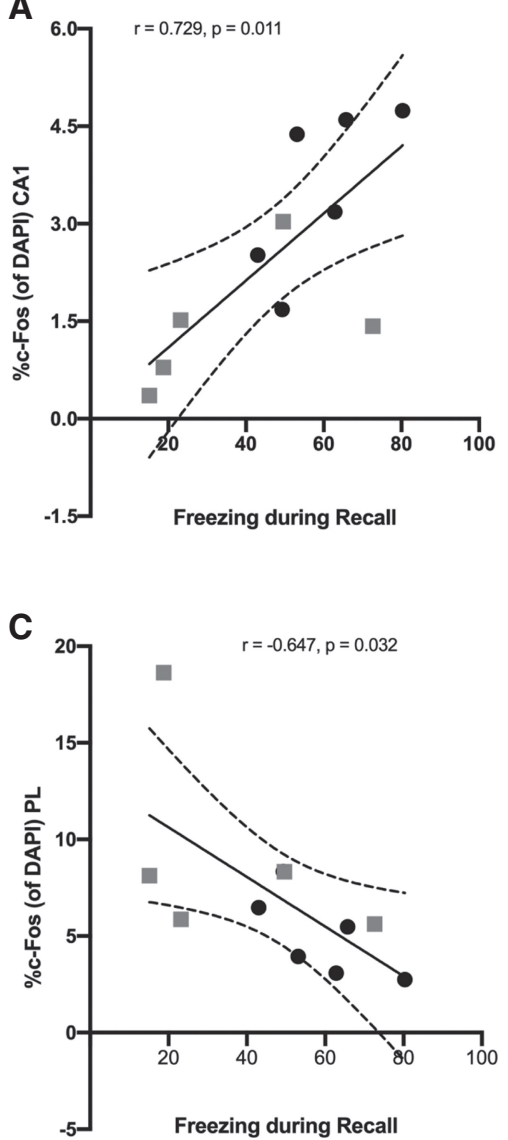

B
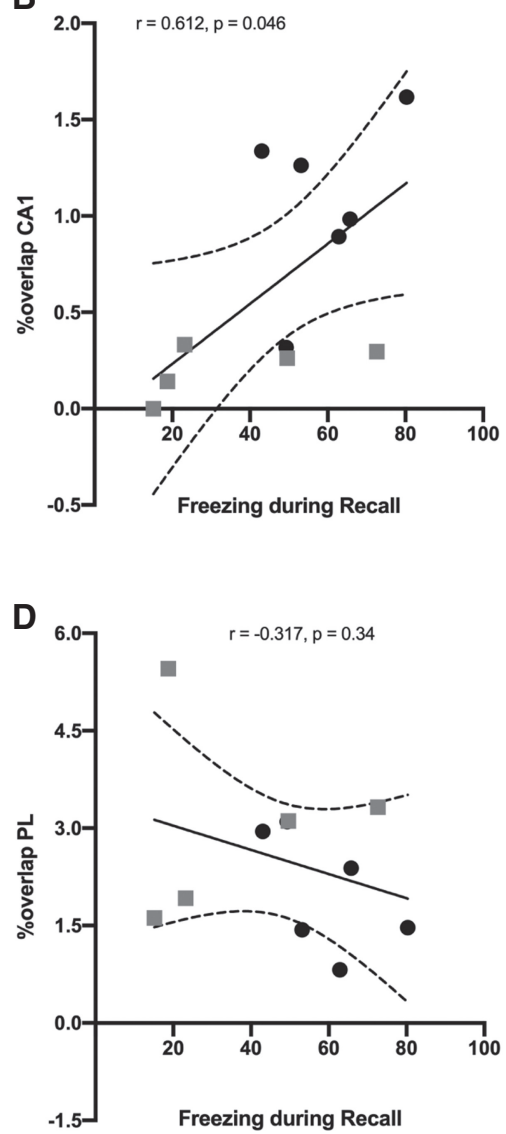

Figure 4. Freezing was positively correlated with c-Fos expression and overlap in the dCA1 and negatively correlated with c-Fos expression in the PL in controls. We ran bivariate correlational analyses between freezing levels during the recall sessions and $c$-Fos expression as well as overlap in the dCA1 and in the PL. In no odor eYFP animals we found that freezing was correlated with $(A)$ c-Fos and $(B)$ overlap in the dCA1 and negatively correlated with $(C)$ c-Fos in the PL. (D) There was no correlation between freezing and overlap in the PL.

systems level. To assess this, we fear-conditioned animals using a four-shock protocol either with or without almond odor present within the training context. We observed increased freezing during training with each successive shock and that odor did not affect the overall learning curves. The lack of group differences during conditioning also suggests that there were no intrinsic effects of the hM4Di virus in the absence of CNO. We then replicated previous work showing that with the passage of time, fear memories are processed to a lesser extent within the HPC and rely on neocortical storage (Teixeira et al. 2006; Lesburgueres et al. 2011; Silva et al. 2018; DeNardo et al. 2019). When fear memory recall following conditioning was tested after $1 \mathrm{~d}$, we observed a more pronounced recruitment of cellular activity compared to the PL. In contrast, when tested after $21 \mathrm{~d}$, we detected increased activity in the PL compared to the dCA1. These data support SC in that episodic-like memory retrieval recruits cortical structures such as the PL at remote compared to recent time points, whereas the HPC is important for initial memory storage (Frankland and Bontempi 2005).

Fear conditioning has been widely used as a model for PTSD in rodent studies (Rasmusson and Charney 1997; Morrison and Ressler 2014; Bali and Jaggi 2015), and fear memories are encoded as engrams across multiple brain regions (Josselyn et al. 2015) and activation of these engrams has been shown to be both necessary and sufficient to drive fear responses (Tonegawa et al. 2015).
However, while the foundation for cortical traces are laid down early during encoding (Lesburgueres et al. 2011; Wang et al. 2012; Cardenas et al. 2019; Corches et al. 2019; Jacques et al. 2019), there is evidence to suggest that the PFC neurons involved in fear memory retrieval are not the same neurons active during encoding (Giannotti et al. 2019; DeNardo et al. 2019). Within the PFC, we specifically looked at the PL for several reasons. In humans, the dorsal anterior cingulate cortex (ACC) has been shown to be hyperactive in response to fearful stimuli in individuals with PTSD (Milad et al. 2007) and comparatively, in rodents the anatomic equivalent of the ACC is the PL (Choi et al. 2010; Laubach et al. 2018). In rodent studies, the PL has been implicated in the expression and renewal of fear responses (Corcoran and Quirk 2007; Sierra-Mercado et al. 2011; Orsini and Maren 2012; Courtin et al. 2014; Fenton et al. 2014; Corches et al. 2019) and increased activity in this region is associated with extinction deficits (Burgos-Robles et al. 2009) as well as increased input to the basolateral amygdala (BLA) (Likhtik et al. 2005; Maren et al. 2013), an output which promotes freezing behavior and fear (Vidal-Gonzalez et al. 2006).

We tested whether presenting an odor during fear conditioning, and then again during retrieval, would alter the dynamics of consolidation in a way that engaged the HPC for a longer period of time (e.g., high intensity training has been shown to have the opposite effect, speeding up the decay of HPC dependency promoting memory generalization; Pedraza et al. 2017). We found that odor influenced this temporal relationship biasing the memory system away from the PFC and toward the HPC, suggesting that retrieval of highly contextual experiences does require the HPC even at remote time points. When recall was tested after 1 d, c-Fos levels were equally elevated in dCA1 in both odor and no-odor groups. However, when we looked at recall at $21 \mathrm{~d}$, these levels declined in the no-odor group but not in the odor animals. Overlaps were also higher and statistically above chance, in the dCA1 at the recent time point for both odor and no odor groups and at the remote time point when odor was present, suggesting that odor can mediate how fear memories are organized.

The present study did not include a group that was exposed to odor during encoding but not during retrieval, opening up the possibility for future experiments to test whether odor as a function of memory possesses the ability to delay translocation of the fear memory trace to the PFC, or if odor presented at the time of retrieval recontextualizes the memory activating the HPC as a result. This data would provide insight into the nuances within the existing debate regarding theories of consolidation: is the HPC always engaged when processing a highly contextual memory (they decontextualize slower) as purported by MTT? Or are these memories equally subject to context generalization, schematization, and decontextualization, but given the ideal cue to evoke recall can become recontextualized thereby stimulating the HPC? Future experiments may also include a group that tests this as well as 
measurements linking $c$-Fos expression to context generalization (Wiltgen and Silva 2007). To further support the modulatory role of odor on SC, we showed that when odor was present, overlaps within the PL decreased to chance levels at both time points, suggesting that odor-associated memories recruit different neurons from encoding to retrieval. It would also be interesting to measure whether overlaps would remain at chance levels if odor had been presented during encoding but not retrieval, as there is a possibility that the PL processes the odor as a new cue, reverting the system back to encoding, despite the observed bias for odor to be processed in the HPC.

Olfaction is a unique sensory modality in that it is the only sense that bypasses the thalamus sending projections directly to the forebrain (Shepherd 2005). Olfactory input is a highly salient sensory cue in both rodents and humans, and guides many different types of behavior from maternal bonding and reproduction, to social hierarchy, foraging, and the detection of pathogens (Doty 1986; Kesslak et al. 1988; Edwards et al. 1990; Fleming et al. 1999; Li et al. 2007; Lübke and Pause 2014; Takahashi et al. 2018). Qualitatively, this may explain why odor as a contextual cue possesses seemingly time-travelling characteristics, (Tulving 2002) where one whiff of your mother's favorite perfume can bring you back to your childhood in an instant. Odor is tightly interconnected with memory. The dentate gyrus (DG) of the HPC is important for keeping highly similar memories and experiences separate, a function called pattern separation (Kesner et al. 2000; Sahay et al. 2011; Schmidt et al. 2012). It has been shown that the ventral DG plays an important role in olfactory learning and memory, and specifically in odor discrimination (Weeden et al. 2014) which may help elucidate how odor-related memories are so resistant to interference. Additionally, there is evidence to suggest that individuals with memory disorders such as Alzheimer's disease experience deficits in processing olfactory memory (Kesslak et al. 1988), potentially due to its reliance on the HPC.

Finally, we assessed whether inhibiting the tagged cellular ensembles in the dCA1 using DREADDs would decrease freezing. Given the up-regulation of the HPC at the recent time point compared to the remote time point, we hypothesized that inhibiting this region would affect memory recall only at $1 \mathrm{~d}$ and not at $21 \mathrm{~d}$. In eYFP controls, we demonstrated that odor promotes hippocampal involvement during remote memory recall, therefore, we also hypothesized that inhibiting the dCA1 would impair memory at the remote time point if the memory was associated with an odor. Behaviorally, we saw no effect of inhibiting the dCA1 with $\mathrm{CNO}$ on recall at $1 \mathrm{~d}$ and unexpectedly there was an increase in freezing at $21 \mathrm{~d}$. The incubation of fear hypothesis originally proposed by Eysenck (1968) states that repeated exposure to an unreinforced conditioned stimulus (i.e., the training context) following acquisition of a classical aversive conditioned response (i.e., freezing) provided that the conditioned stimulus (i.e., the shock) is a strong stimulus, will serve to enhance the conditioned response over time (Richards and Martin 1990). In previous rodent studies, which have examined fear memory recall across recent and remote time points, fear responses related to the training context tended to either stay stable (Wiltgen and Silva 2007; Poulos et al. 2016) or strengthen over time (Houston et al. 1999; Balogh et al. 2002; Frankland et al. 2004; Poulos et al. 2016) supporting Eysenck's hypothesis. However, there have also been human studies where this effect was not observed (Richards and Martin 1990), and in the current study, we saw a decline in freezing over time. While we did not test fear generalization, it is possible that this decline in the conditioned response was accompanied by an increase in generalization (Wiltgen and Silva 2007). If our animals had not shown this decrease, we speculate that the behavioral differences between eYFP and DREADDs animals at the remote time point would not have been observed. The majority of studies reporting incubation of fear looked at recall between 28-36 d later (Balogh et al. 2002; Frankland et al. 2004; Wiltgen and Silva 2007; Poulos et al. 2016; Germer et al. 2019) with one study (Siegmund and Wotjak 2007) claiming maximal fear expression occurring at $28 \mathrm{~d}$, whereas we tested our mice at $21 \mathrm{~d}$ which may not be long enough for an effect of fear incubation to emerge. Interestingly, Houston et al. (1999) found that fear incubation is less pronounced in older rats (27 mo). Together, the conclusions from our behavioral data should be tempered nonetheless, chemogenetic inhibition of dCA1 engram cells using DREADDs did not decrease freezing at either time point.

Unexpectedly, we also saw high levels of $c$-Fos expression in all groups that received DREADDs in the dCA1. Theoretically, these neurons should effectively be silenced and show very little, if any c-Fos expression. DREADDs are G-protein coupled receptors (GPCRs) that have been genetically engineered to allow minimal constitutive activity when they are introduced by viral-mediated gene transfer directly into the brain, thus behavior in the animal is not affected by their presence (Pei et al. 2008). DREADDs do not have endogenous ligands as they are activated only by the synthetic ligand, $\mathrm{CNO}$, an inert compound that does not induce any other activity in the rodent brain aside from binding to these designer GPCRs (Pei et al. 2008). The inhibitory DREADDs construct that we used contained the gene hM4Di (Gi) which originated from the human muscarinic receptor where induced point mutations allow inefficacy of the endogenous ligand acetylcholine, and efficacy of $\mathrm{CNO}$, where activation of hM4Di receptors can inhibit neurons in a reversible manner (Armbruster et al. 2007). Confirmed using extracellular in vivo recordings measured 30 min later, $\mathrm{CNO}$ administered at $5 \mathrm{mg} / \mathrm{kg}$ was able to inhibit neuronal firing rates in c-Fos-tTA transgenic mice injected with an AAV virus carrying the hM4Di gene under the control of the hSyn 1 promoter (Ryan et al. 2015). Following this time frame, as DREADDs are reversible, firing rates rebounded back to steady state. Several other electrophysiology studies have produced similar findings (Armbruster et al. 2007; Ferguson et al. 2011; Parnaudeau et al. 2013; Sano et al. 2014). For the most part, other studies which have established the inhibitory nature of this gene have tested whether CNO sufficiently hyperpolarizes neurons in slice preparations with a CNO bath-application onto cultured hippocampal cells in vitro. The degree to which CNO can hyperpolarize the cell has been shown to be dose-dependent (Zhu et al. 2014). It is possible that the dose we chose $(3 \mathrm{mg} / \mathrm{kg}$ ) was too low to observe behavioral effects, and potentially our dose was not sufficient to cross the threshold of decreased firing to silence neurons but resulted in "quieting" neurons rather than shutting them off completely. However, many other studies that have reported observable effects used lower doses (1 mg/kg) (Andero et al. 2014; Mahler et al. 2014; Sweeney and Yang 2015; Parfitt et al. 2017; Chiang et al. 2018).

We have explored several possible explanations for our DREADDs results. The most parsimonious is that CNO itself produced a cellular perturbation that did not fully manifest into a behavioral readout. Thus, although we failed to see a behavioral effect, we nevertheless observed alterations in c-Fos expression. It is also possible that our virus targeted interneurons and therefore rather than silencing excitatory pyramidal cells in the dCA1, we inhibited inhibitory interneurons thereby disinhibiting adjacent excitatory neurons causing an increase in activity. Theoretically, this fits with our behavioral results since further increases in activity in the dCA1 would not have contributed to further freezing, as a ceiling effect was potentially reached. In contrast, in c-Fos-tTA transgenic mice (Reijmers et al. 2007) transduced with the DOX-regulated AAV9-TRE-ChR2-eYFP virus, engram labeling was restricted to excitatory neurons, as no overlap was detected somatically between ChR2 positive cells and inhibitory gammaaminobutyric acid (GABA) positive cells (Liu et al. 2012). To date, 
no assessment of the kinetics of $\mathrm{CNO}$ based neural inactivation has been conducted in wild-type animals that have been injected with the $c$-Fos-tTA-TRE-hM4Di-eYFP virus, although in a recent paper our group too observed similar results of $c$-Fos expression in the BLA (Chen et al. 2019).

One of the striking differences between the DREADDs system we used and what has been used in the majority of other studies is that our system is a tet-off system where hM4Di is only expressed in a subset of cells transduced ( 20\%). Targeted cells specifically consist of the fear engram cells active during tagging/encoding and not all of the neurons in that particular brain region. In a recent paper, using c-Fos-tTA transgenic mice injected with a DOX-regulated TRE-ArchT-GFP virus to optogenetically silence cocaine-place engram neurons in the dCA1, light delivery led to inhibition in the targeted neurons accompanied by the simultaneous emergence of activity in nontargeted, alternative neurons in the vicinity. They found that their manipulation caused a disengagement from initially recruited cells (during encoding) and the activation of an alternative spatial map (Trouche et al. 2016). Although this study was conducted using optogenetics, it is possible that silencing engram cells in the dCA1 resulted in the recruitment of adjacent nonengram cells. This would explain how $c$-Fos levels were elevated, but overlaps were not statistically above chance, following $\mathrm{CNO}$ injections in hM4Di mice. Furthermore, promoterdependent differential hM4Di virus expression has been observed (Lopez et al. 2016).

It is not surprising that we would see these compensatory, off-target effects following acute perturbation of the steady-state internal dynamics of the brain possibly interfering with the excitatory-inhibitory balance in the dCA1 (Otchy et al. 2015). This is colloquially known as the "whack a mole" effect, once you hit a mole another one pops up. In this case, silencing a neuron is like hitting a mole. We also saw an increase in $c$-Fos in the PL following inhibition in the dCA1. This was observed in all groups except the group tested after $1 \mathrm{~d}$ that was exposed to odor. Again, given the complex excitatory-inhibitory feedback networks within the HPC and between the HPC and the PFC, inhibition or perturbation in the dCA1 with DREADDs would not necessarily result in a decrease in firing in the PL (Schmidt et al. 2019). Schmidt et al. (2019) found that some neurons increased, and some neurons decreased their firing rate following $\mathrm{CNO}$ injection in mice transfected with the hM4Di gene in the PFC under the CAMKIIa promoter. Interestingly, in the current study, perturbing the dCA1 at the recent time point redirected processing during memory retrieval to the PL in the no-odor group but not the odor group. This further supports our hypotheses and suggests that to some degree, odor-associated fear memories are less flexible in the sense that they require the HPC for processing but may be more malleable in this region. We believe that, together, this presents a putative new target for PTSD research. Current therapeutic interventions often involve exposure therapy, and reactivating a previously consolidated, odor-associated fear memory in the presence of the associated odor may bias the memory system allocating the trace to the HPC for processing. Theoretically, this may help focus intervention strategies to a particular locus or node in the brain that can be combined with other treatments. Additionally, future studies may involve intersectional analysis involving this theory and the use of optogenetics.

Previous research has demonstrated a connection between the expression of excitatory DREADDs and c-Fos (Garner et al. 2012; Roy et al. 2019). To assess whether there was a link between increases in $c$-Fos expression observed following inhibition of the dCA1 with DREADDs and our behavioral data where we saw an increase in freezing in animals that received $\mathrm{CNO}$ at the remote time point, we ran a correlational analysis. Several studies have shown a positive correlation between conditioned freezing and c-Fos expression in the HPC (Radulovic et al. 1998; Strekalova et al. 2003; Knapska and Maren 2009), however, some studies have shown a dissociation (Singewald 2007; Plendl and Wotjak 2010; Mastrodonato et al. 2018). We only found significant correlations in our eYFP no odor group where conditioned freezing was positively correlated with $c$-Fos levels and the percentage of overlap in the dCA 1 and negatively correlated with c-Fos expression in the PL. Since we found no correlations between these measures in the DREADDs groups, the increase in freezing that we saw in the DREADDs mice at the remote time point cannot be attributed to the increased $c$-Fos expression seen in these mice in the dCA1 and in the PL following CNO administration. Moreover, the time interval between CNO injection and perfusion was $120 \mathrm{~min}$, and it remains possible that by this time $c$-Fos levels started to rebound following neuronal inhibition and that we would have seen lower $c$-Fos levels and significant correlations if we had sacrificed the animals slightly earlier.

In summary, our histological results provide insight into the molecular dynamics related to activity-dependent, DOX-regulated inhibitory DREADDs, while also demonstrating plasticity in the process of memory consolidation at the systems level whereby even remote memories are amenable to modulation by contextual cues such as odor. A better understanding of how memories are layered, comprised of contextual information at the level of the engram localized to specific brain regions (Vetere et al. 2019) may provide therapeutic insight to the convergence of emotional processing and PTSD symptomology (Daniels and Vermetten 2016).

\section{Materials and Methods}

\section{Animals}

Fifty one wild-type male c57BL/6 mice (2-3 mo of age; Charles River Labs) weighing 18-25 $\mathrm{g}$ at the time of arrival were housed in groups of 2-5 mice per cage. Mice were kept on a regular light cycle 12:12 h light-dark in a temperature and humidity-controlled colony room. Cages were changed once a week and contained cardboard huts and nesting material for enrichment. Upon arrival in the facility, mice were placed on a $40 \mathrm{mg} / \mathrm{kg}$ DOX diet (Bio-Serv, product F4159, Lot 226766) and left undisturbed for a minimum of $3 \mathrm{~d}$ prior to surgery with access to food and water ad libitum. They were then handled for two consecutive days for 2 min each day. The following day they underwent surgery. All subjects were treated in accordance with protocol 17-008 approved by the Institutional Animal Care and Use Committee at Boston University. The behavioral results reported are based on data from a total of 51 experimental and control animals. Due to a loss of tissue histological data reported is based on 44 animals for CA1 and 45 animals for PL.

\section{Stereotaxic surgery and virus microinjections}

Aseptic surgeries were carried out with mice mounted into a stereotaxic frame (Kopf Instruments) with skull flat. They were anesthetized with $4 \%$ isoflurane and $70 \%$ oxygen for induction with isoflurane at $2 \%$ to maintain anesthesia during surgery. A small amount of $2 \%$ lidocaine (Clipper Distributing Company) was placed on the skull as a topical analgesic and a small hole was drilled above each injection site. Animals received four microinjections, bilateral injections into the dorsal CA1 (dCA1) (Fig. 1A,B) and the prelimbic cortex (PL) (Fig. 1A,C) via a $10 \mu \mathrm{L}$ gas-tight Hamilton syringe attached to a micro-infusion pump (UMP3, World Precision Instruments) which occurred at a rate of $100 \mathrm{~nL}$ $\mathrm{min}^{-1}$. Coordinates are given relative to Bregma (in $\mathrm{mm}$ ). In the PL, mice were injected with a viral cocktail of AAV9-cFos-tTa (titre: $1 \mathrm{E}+13 \mathrm{GC} / \mathrm{mL}$ ) and TRE-eYFP (titre: $3 \mathrm{E}+13 \mathrm{GC} / \mathrm{mL}$ ) in a volume of $400 \mathrm{~nL} /$ side at AP: +1.9 , ML: \pm 0.3 , DV: -1.9 . The dCA1 was targeted at AP: -2.0, ML: $\pm 1.5, \mathrm{DV}:-1.2$, with mice receiving a cocktail of AAV9-cFos-tTa and either TRE-hM4Di-eYFP (titre: $2.5 \mathrm{E}+13 \mathrm{GC} /$ $\mathrm{mL}$ ) (DREADDs) or TRE-eYFP (eYFP) in a volume of $550 \mathrm{~nL} /$ side. 
Injectors were left in place for $1 \mathrm{~min}$ following each injection to avoid liquid backflow. Mice were then sutured, received $0.2 \mathrm{~mL}$ physiological sterile saline $(0.9 \%$, s.c.) and $0.1 \mathrm{~mL}$ of a $0.03 \mathrm{mg} /$ mL buprenorphine solution (i.p.) at the end of the surgery, and were placed on a heating pad and given hydrogel. Mice were given an additional injection buprenorphine $(0.1 \mathrm{~mL}, 0.03 \mathrm{mg} / \mathrm{mL}$, i.p.) the next day. Except for cage changes, having their tails marked with a skin marker every $24-48 \mathrm{~h}$, and being weighed, mice were left undisturbed for a 10-d period following surgery to allow for recovery and virus expression.

\section{Behavioral testing: fear conditioning and recall}

Mice were habituated to $2 \%$ DMSO injections in sterile saline $(0.9 \%$, i.p) $3 \mathrm{~d}$ prior to fear conditioning. DOX diet was replaced with standard rodent chow (ad libitum) $42 \mathrm{~h}$ prior to behavioral tagging. Half of the animals were fear-conditioned in the presence of almond extract-soaked gauze in a plastic container with holes (ODOR) in the conditioning chambers (Coulbourn) while the other half were just given the tubes without the odor (NO ODOR). The fear conditioning session lasted $500 \mathrm{sec}$. Mice received four shocks during this session: first shock at $198 \mathrm{sec}$, second at $280 \mathrm{sec}$, third at $360 \mathrm{sec}$, and fourth at $440 \mathrm{sec}$ (Costanzi et al. 2014; Redondo et al. 2014) ( 2 sec duration, $1.5 \mathrm{~mA}$ intensity). At the end of the session, mice were placed back on DOX (ad libitum) and placed in a holding tank until all cage mates had been fear-conditioned and then all mice were placed back with cage mates in a clean home cage. Mice were returned to the original fear-conditioning context for a Recall session either $1 \mathrm{~d}$ (RECENT) or $21 \mathrm{~d}$ later (REMOTE) with the same odor conditions they received during conditioning. Thirty minutes prior to the recall session, all mice were injected with clozapine-N-oxide (CNO) and 90 min after the recall session mice were euthanized. We also included a control group that was tested at the RECENT time point with NO ODOR, however these mice were given saline injections (2\%DMSO in sterile saline $0.9 \%$, i.p.) instead of $\mathrm{CNO}(n=4)$. Each conditioning chamber had a camera mounted on the roof for video recording. Video was fed into a computer running Freeze Frame/View software (Coulbourn Instruments) where freezing was defined as a bout of immobility lasting $1.25 \mathrm{sec}$ or longer.

\section{Drugs: use of clozapine-N-oxide}

Half of the animals were injected with an inhibitory DREADDs virus (hM4Di) fused to an eYFP reporter while the other half were given just eYFP. To inhibit neuronal firing (Pei et al. 2008; Dong et al. 2010; Ferguson et al. 2011; Zhu and Roth 2015; Roth 2016) in cells transfected with DREADDs (Mahler et al. 2014; Zhu and Roth 2015), all mice (except for the saline control group) were injected with CNO, obtained from NIH: NIDA Drug Supply Program (NIMH C-929; batch ID: 14073-1) and prepared in a concentration of $0.6 \mathrm{mg} / \mathrm{mL}$ in sterile saline $(0.9 \%)$ and $2 \%$ DMSO. Thirty minutes prior to the recall session this was administered i.p. at a dose of $3 \mathrm{mg} / \mathrm{kg}$.

\section{Immunohistochemistry}

Mice were overdosed with isoflurane and perfused transcardially with $\left(4^{\circ} \mathrm{C}\right)$ phosphate-buffered saline (PBS) followed by $4 \%$ paraformaldehyde (PFA) in PBS. Brains were extracted and stored overnight in PFA at $4^{\circ} \mathrm{C}$ and transferred to PBS solution the following day. Brains were sliced into $50 \mu \mathrm{m}$ coronal sections with a vibratome (Leica, VT100S) and collected in cold PBS. Sections were blocked for $2 \mathrm{~h}$ at room temperature in $1 \times$ phosphate-buffered saline $+2 \%$ Triton (PBS-T) and 5\% normal goat serum (NGS) on a shaker. Sections were transferred to well plates containing primary antibodies made in PBS-T (1:1000 rabbit anti-c-Fos [SySy]; 1:5000 chicken anti-GFP [Invitrogen]) and incubated on a shaker at $4^{\circ} \mathrm{C}$ for $48 \mathrm{~h}$. Sections were then washed in PBS-T for $10 \mathrm{~min}(\times 3)$, followed by a $2 \mathrm{~h}$ incubation with secondary antibody (1:200 Alexa 555 anti-rabbit [Invitrogen]; 1:200 Alexa 488 anti-chicken [Invitrogen] made in PBS-T). Following three additional $10 \mathrm{~min}$ washes in PBS-T, sections were mounted onto micro slides (VWR
International, LCC). Nuclei were counterstained with DAPI added to Vectashield HardSet Mounting Medium (Vector Laboratories, Inc), slides were then coverslipped and put in the fridge overnight. The following day the edges were sealed with clear nail-polish and the slides were stored in a slide box in the fridge until imaging.

\section{Fluorescent confocal image acquisition and analysis}

Images were collected from coronal sections using a fluorescent confocal microscope (Zeiss LSM 800 with airyscan) at $20 \times$ magnification. For each animal, in the PL, 2-3 Z-stacks (step size $0.94 \mu \mathrm{m}$ ) were taken per hemisphere from 2-3 different slices yielding 4-6 total $z$-stacks per animal. In the dCA1, $z$-stacks (step size 0.94 $\mu \mathrm{m})$ were obtained from both hemispheres from 3-4 different slices. Per slice two stacks were taken in the left hemisphere, one in the dorsomedial CA1 and one in the dorsolateral CA1. The values for these were summed. Two images were also taken in the right hemisphere, and these also summed. Data from each hemisphere was then pooled and the mean for the total 6-8 z-stacks were computed. The total number of DAPI positive (+) neurons were counted using Image $\mathrm{J} / \mathrm{Fiji}$ (https://imagej.nih.gov/ij/). In addition, the number of eYFP+ (cells tagged during fear conditioning), c-Fos+ (cells active at the time of fear memory recall), and eYFP+ and c-Fos+ (cells active in both behavioral epochs) neurons in the dCA1 and PL were quantified to measure the number of active cells during defined behavioral tasks. Percentage of immunoreactive neurons was defined as a proportion of total DAPI-labeled cells. Chance overlap was calculated as the percentage of eYFP+ neurons multiplied by the percentage of $c$-Fos + neurons over the total number of DAPI neurons.

\section{Statistical analysis}

Calculated statistics are presented as means \pm SEM. To analyze differences, we used three-way analyses of variance (ANOVA) [RECALL (between-subject factor-two levels: RECENT and REMOTE time points) $\times$ ODOR (between-subject factor-two levels: ODOR and NO ODOR) $\times$ VIRUS (between-subject factor-two levels: eYFP and DREADDS)]. When appropriate, follow-up comparisons (two-way ANOVAs, independent T-tests) and post-hoc analyses (Tukey's HSD, or Mann-Whitney) were conducted. When Fear Conditioning and Recall sessions were divided into bins, these data were analyzed using Repeated Measures (RM) three-way ANOVAs [ODOR (between-subject factor-two levels: ODOR and NO ODOR) $\times$ VIRUS (between-subject factor-two levels: eYFP and DREADDS) $\times$ TIME (within-subject factor-two levels: PRE and POST Shock/or five levels: MINUTES 1-5) or $\times$ SHOCK (within-subject factor-four levels: SHOCK 1-4). Comparisons between the percentage of overlap against chance were also conducted using three-way RM ANOVAs [ODOR (between-subject factor-two levels: ODOR and NO ODOR) $\times$ VIRUS (between-subject factor-two levels: eYFP and DREADDS) $\times$ CHANCE (within-subject factor-two levels: OVERLAP and CHANCE). Bivariate correlational analyses were performed using Pearson's Correlation Coefficient. All statistical tests assumed an alpha level of 0.05 . For all figures, ${ }^{*}=P<0.05,{ }^{* *}=P<0.01,{ }^{* * *}=P<$ 0.001 .

\section{Competing interest statement}

The authors declare no competing interests.

\section{Acknowledgments}

We would like to thank Dr. Susumu Tonegawa and his laboratory for providing the activity-dependent virus cocktail. We would like to thank the NIH for providing us with CNO. We would also like to thank the members of the Ramirez laboratory for helpful comments and suggestions. This work was supported by NIH Early Independence Award (DP5 OD023106-01), a Young Investigator Grant from the Brain and Behavior Research 
Foundation, a Ludwig Family Foundation Grant, and the McKnight Foundation Memory and Cognitive Disorders Award. Author contributions: All authors contributed to the design of the experiments and data collection. S.L.G. and A.H.F. conducted all behavioral experiments, and S.L.G., A.H.F., O.M., and H.L. contributed to quantification of the histological data. S.L.G., A.H.F. and S.R. wrote the paper. All authors edited and commented upon the manuscript.

\section{References}

Andero R, Dias BG, Ressler KJ. 2014. A role for Tac2, NkB, and Nk3 receptor in normal and dysregulated fear memory consolidation. Neuron 83: 444 454. doi:10.1016/j.neuron.2014.05.028

Armbruster BN, Li X, Pausch MH, Herlitze S, Roth BL. 2007. Evolving the lock to fit the key to create a family of $\mathrm{G}$ protein-coupled receptors potently activated by an inert ligand. Proc Natl Acad Sci 104: 5163-5168. doi:10.1073/pnas.0700293104

Arshamian A, Iannilli E, Gerber JC, Willander J, Persson J, Seo H-S, Hummel T, Larsson M. 2013. The functional neuroanatomy of odor evoked autobiographical memories cued by odors and words. Neuropsychologia 51: 123-131. doi:10.1016/j.neuropsychologia.2012.10.023

Bali A, Jaggi AS. 2015. Electric foot shock stress: a useful tool in neuropsychiatric studies. Rev Neurosci 26: 655-677. doi:10.1515/ revneuro-2015-0015

Balogh SA, Radcliffe RA, Logue SF, Wehner JM. 2002. Contextual and cued fear conditioning in C57BL/6J and DBA/2J mice: context discrimination and the effects of retention interval. Behav Neurosci 116: 947-957. doi:10.1037/0735-7044.116.6.947

Bayley PJ, Hopkins RO, Squire LR. 2003. Successful recollection of remote autobiographical memories by amnesic patients with medial temporal lobe lesions. Neuron 38: 135-144. doi:10.1016/S0896-6273(03)00156-9

Bayley PJ, Gold JJ, Hopkins RO, Squire LR. 2005. The neuroanatomy of remote memory. Neuron 46: 799-810. doi:10.1016/j.neuron.2005.04 .034

Berntsen D, Thomsen DK. 2005. Personal memories for remote historical events: accuracy and clarity of flashbulb memories related to World War II. J Exp Psychol Gen 134: 242-257. doi:10.1037/0096-3445.134.2.242

Blumenfeld RS, Ranganath C. 2007. Prefrontal cortex and long-term memory encoding: an integrative review of findings from neuropsychology and neuroimaging. Neuroscience 13: 280-291. doi:10 $.1177 / 1073858407299290$

Bonaccorsi J, Cintoli S, Mastrogiacomo R, Baldanzi S, Braschi C, Pizzorusso T, Cenni MC, Berardi N. 2013. System consolidation of spatial memories in mice: effects of enriched environment. Neural Plast 2013: 956312. doi:10.1155/2013/956312

Bonnici HM, Chadwick MJ, Lutti A, Hassabis D, Weiskopf N, Maguire EA. 2012. Detecting representations of recent and remote autobiographical memories in vmPFC and hippocampus. J Neurosci 32: 16982-16991. doi:10.1523/JNEUROSCI.2475-12.2012

Broadbent NJ, Squire LR, Clark RE. 2006. Reversible hippocampal lesions disrupt water maze performance during both recent and remote memory tests. Learn Mem 13: 187-191. doi:10.1101/lm.134706

Burgos-Robles A, Vidal-Gonzalez I, Quirk GJ. 2009. Sustained conditioned responses in prelimbic prefrontal neurons are correlated with fear expression and extinction failure. J Neurosci 29: 8474-8482. doi:10 .1523/JNEUROSCI.0378-09.2009

Cardenas A, Blanca M, Dimitrov E. 2019. Persistent pain intensifies recall of consolidated fear memories. Neurobiol Stress 10: 100163. doi:10.1016/j .ynstr.2019.100163

Chen BK, Murawski NJ, Cincotta C, McKissick O, Finkelstein A, Hamidi AB, Merfeld E, Doucette E, Grella SL, Shpokayte M, et al. 2019. Artificially enhancing and suppressing hippocampus-mediated memories. Curr Biol 29: 1885-1894.e4. doi:10.1016/j.cub.2019.04.065

Chiang M-C, Huang AJY, Wintzer ME, Ohshima T, McHugh TJ. 2018. A role for CA3 in social recognition memory. Behav Brain Res 354: 22-30. doi:10.1016/j.bbr.2018.01.019

Choi DC, Maguschak KA, Ye K, Jang S-W, Myers KM, Ressler KJ. 2010. Prelimbic cortical BDNF is required for memory of learned fear but not extinction or innate fear. Proc Natl Acad Sci 107: 2675-2680. doi:10 $.1073 /$ pnas.0909359107

Corches A, Hiroto A, Bailey TW, Speigel JH, Pastore J, Mayford M, Korzus E. 2019. Differential fear conditioning generates prefrontal neural ensembles of safety signals. Behav Brain Res 360: 169-184. doi:10.1016/j .bbr.2018.11.042

Corcoran KA, Quirk GJ. 2007. Activity in prelimbic cortex is necessary for the expression of learned, but not innate, fears. J Neurosci 27: 840-844. doi:10.1523/JNEUROSCI.5327-06.2007

Costanzi M, Saraulli D, Cannas S, D’Alessandro F, Florenzano F, Rossi-Arnaud C, Cestari V. 2014. Fear but not fright: re-evaluating traumatic experience attenuates anxiety-like behaviors after fear conditioning. Front Behav Neurosci 25: 279. doi:10.3389/fnbeh.2014 .00279

Courtin J, Chaudun F, Rozeske RR, Karalis N, Gonzalez-Campo C, Wurtz H, Abdi A, Baufreton J, Bienvenu TCM, Herry C. 2014. Prefrontal parvalbumin interneurons shape neuronal activity to drive fear expression. Nature 505: 92-96. doi:10.1038/nature12755

Daniels JK, Vermetten E. 2016. Odor-induced recall of emotional memories in PTSD-review and new paradigm for research. Exp Neurol 284: 168 180. doi:10.1016/j.expneurol.2016.08.001

Debiec J, LeDoux JE, Nader K. 2002. Cellular and systems reconsolidation in the hippocampus. Neuron 36: 527-538. doi:10.1016/S0896-6273(02) 01001-2

DeNardo LA, Liu CD, Allen WE, Adams EL, Friedmann D, Fu L, Guenthner CJ, Tessier-Lavigne M, Luo L. 2019. Temporal evolution of cortical ensembles promoting remote memory retrieval. Nat Neurosci 22: 460469. doi:10.1038/s41593-018-0318-7

Deng W, Mayford M, Gage FH. 2013. Selection of distinct populations of dentate granule cells in response to inputs as a mechanism for pattern separation in mice. Elife 2: e00312. doi:10.7554/eLife.00312

de Sousa AF, Cowansage KK, Zutshi I, Cardozo LM, Yoo EJ, Leutgeb S, Mayford M. 2019. Optogenetic reactivation of memory ensembles in the retrosplenial cortex induces systems consolidation. Proc Natl Acad Sci 116: 8576-8581. doi:10.1073/pnas.1818432116

Dong S, Allen JA, Farrell M, Roth BL. 2010. A chemical-genetic approach for precise spatio-temporal control of cellular signaling. Mol Biosyst 6: 1376. doi: $10.1039 / \mathrm{c} 002568 \mathrm{~m}$

Doron A, Goshen I. 2018. Investigating the transition from recent to remote memory using advanced tools. Brain Res Bull 141: 35-43. doi:10.1016/ .brainresbull.2017.09.005

Doty RL. 1986. Odor-guided behavior in mammals. Experientia 42: 257-271. doi:10.1007/BF01942506

Edwards DA, Griffis KT, Tardivel C. 1990. Olfactory bulb removal: effects on sexual behavior and partner-preference in male rats. Physiol Behav 48: 447-450. doi:10.1016/0031-9384(90)90342-2

Eysenck HJ. 1968. A theory of the incubation of anxiety-fear responses. Behav Res Ther 6: 309-321. doi:10.1016/0005-7967(68)90064-8

Fenton GE, Halliday DM, Mason R, Stevenson CW. 2014. Medial prefrontal cortex circuit function during retrieval and extinction of associative learning under anesthesia. Neuroscience 265: 204-216. doi:10.1016/j .neuroscience.2014.01.028

Ferguson SM, Eskenazi D, Ishikawa M, Wanat MJ, Phillips PEM, Dong Y, Roth BL, Neumaier JF. 2011. Transient neuronal inhibition reveals opposing roles of indirect and direct pathways in sensitization. Nat Neurosci 14: 22-24. doi:10.1038/nn.2703

Fernández-Lansac V, Crespo M. 2017. Quality of memories in women abused by their intimate partner: analysis of traumatic and nontraumatic narratives. J Trauma Stress 30: 80-87. doi:10.1002/jts .22154

Fleming AS, O'Day DH, Kraemer GW. 1999. Neurobiology of mother-infant interactions: experience and central nervous system plasticity across development and generations. Neurosci Biobehav Rev 23: 673-685. doi:10.1016/S0149-7634(99)00011-1

Frankland PW, Bontempi B. 2005. The organization of recent and remote memories. Nat Rev Neurosci Neurosci 6: 119-130. doi:10.1038/nrn1607

Frankland PW, Bontempi B, Talton LE, Kaczmarek L, Silva AJ. 2004. The involvement of the anterior cingulate cortex in remote contextual fear memory. Science 304: 881-883. doi:10.1126/science.1094804

Garner AR, Rowland DC, Hwang SY, Baumgaertel K, Roth BL, Kentros C, Mayford M. 2012. Generation of a synthetic memory trace. Science 335: 1513-1516. doi:10.1126/science.1214985

Germer J, Kahl E, Fendt M. 2019. Memory generalization after one-trial contextual fear conditioning: effects of sex and neuropeptide $S$ receptor deficiency. Behav Brain Res 361: 159-166. doi:10.1016/j.bbr.2018.12 .046

Giannotti G, Heinsbroek JA, Yue AJ, Deisseroth K, Peters J. 2019. Prefrontal cortex neuronal ensembles encoding fear drive fear expression during long-term memory retrieval. Sci Rep 9: 10709. doi:10.1038/ s41598-019-47095-7

Gilboa A, Winocur G, Grady CL, Hevenor SJ, Moscovitch M. 2004. Remembering our past: functional neuroanatomy of recollection of recent and very remote personal events. Cereb Cortex 14: 1214-1225. doi:10.1093/cercor/bhh082

Glachet O, El Haj M. 2019. Emotional and phenomenological properties of odor-evoked autobiographical memories in Alzheimer's disease. Brain Sci 9: 135. doi:10.3390/brainsci9060135

Gonzalez C, Kramar C, Garagoli F, Rossato JI, Weisstaub N, Cammarota M, Medina JH. 2013. Medial prefrontal cortex is a crucial node of a rapid learning system that retrieves recent and remote memories. Neurobiol Learn Mem 103: 19-25. doi:10.1016/j.nlm.2013.04.006 
Goshen I, Brodsky M, Prakash R, Wallace J, Gradinaru V, Ramakrishnan C, Deisseroth K. 2011. Dynamics of retrieval strategies for remote memories. Cell 147: 678-689. doi:10.1016/j.cell.2011.09.033

Hebb D. 1949. The organization of behavior: a neuropsychological theory. John Wiley \& Sons Inc, Mahwah, NJ.

Holtmaat A, Caroni P. 2016. Functional and structural underpinnings of neuronal assembly formation in learning. Nat Neurosci 19: 1553-1562. doi:10.1038/nn.4418

Houston FP, Stevenson GD, McNaughton BL, Barnes CA. 1999. Effects of age on the generalization and incubation of memory in the F344 rat. Learn Mem 6: 111-119.

Irish M, Lawlor BA, O'Mara SM, Coen RF. 2010. Exploring the recollective experience during autobiographical memory retrieval in amnestic mild cognitive impairment. J Int Neuropsychol Soc 16: 546-555. doi:10.1017/ S1355617710000172

Jacques A, Chaaya N, Hettiarachchi C, Carmody M-L, Beecher K, Belmer A, Chehrehasa F, Bartlett S, Battle AR, Johnson LR. 2019. Microtopography of fear memory consolidation and extinction retrieval within prefrontal cortex and amygdala. Psychopharmacology (Berl) 236: 383-397. doi:10 .1007/s00213-018-5068-4

Janssen SMJ, Rubin DC, St Jacques PL. 2011. The temporal distribution of autobiographical memory: changes in reliving and vividness over the life span do not explain the reminiscence bump. Mem Cognit 39: 1-11. doi:10.3758/s13421-010-0003-x

Josselyn SA, Köhler S, Frankland PW. 2015. Finding the engram. Nat Rev Neurosci 16: 521-534. doi:10.1038/nrn4000

Kapur N, Brooks DJ. 1999. Temporally-specific retrograde amnesia in two cases of discrete bilateral hippocampal pathology. Hippocampus 9: 247254. doi:10.1002/(SICI)1098-1063(1999)9:3<247::AID-HIPO5>3.0.CO ;2-W

Kensinger EA, Schacter DL. 2008. Neural processes supporting young and older adults' emotional memories. J Cogn Neurosci 20: 1161-1173. doi: $10.1162 /$ jocn.2008.20080

Kesner RP, Gilbert PE, Wallenstein GV. 2000. Testing neural network models of memory with behavioral experiments. Curr Opin Neurobiol 10: 260265.

Kesslak JP, Cotman CW, Chui HC, Van den Noort S, Fang H, Pfeffer R, Lynch G. 1988. Olfactory tests as possible probes for detecting and monitoring Alzheimer's disease. Neurobiol Aging 9: 399-403. doi:10.1016/ S0197-4580(88)80087-3

Kirchhoff BA, Wagner AD, Maril A, Stern CE. 2000. Prefrontal-temporal circuitry for episodic encoding and subsequent memory. J Neurosci 20: 6173-6180. doi:10.1523/JNEUROSCI.20-16-06173.2000

Kirwan CBC, Bayley PJ, Galvan V V, Squire LRL. 2008. Detailed recollection of remote autobiographical memory after damage to the medial temporal lobe. Proc Natl Acad Sci 105: 2676-2680. doi:10.1073/pnas .0712155105

Kitamura T, Ogawa SK, Roy DS, Okuyama T, Morrissey MD, Smith LM, Redondo RL, Tonegawa S. 2017. Engrams and circuits crucial for systems consolidation of a memory. Science 356: 73-78. doi:10.1126/science .aam6808

Knapska E, Maren S. 2009. Reciprocal patterns of c-Fos expression in the medial prefrontal cortex and amygdala after extinction and renewal of conditioned fear. Learn Mem 16: 486-493. doi:10.1101/lm.1463909

Laubach M, Amarante LM, Swanson K, White SR. 2018. What, if anything, is rodent prefrontal cortex? eNeuro 5. doi:10.1523/ENEURO.0315-18 .2018 .

Lechner H, Squire L, Byrne JH. 1999. 100 years of consolidation remembering Müller and Pilzecker. Learn Mem 6: 77-87.

Lesburgueres E, Gobbo OL, Alaux-Cantin S, Hambucken A, Trifilieff $P$, Bontempi B. 2011. Early tagging of cortical networks is required for the formation of enduring associative memory. Science 331: 924-928. doi:10.1126/science.1196164

Li W, Moallem I, Paller KA, Gottfried JA. 2007. Subliminal smells can guide social preferences. Psychol Sci 18: 1044-1049. doi:10.1111/j.1467-9280 2007.02023x

Likhtik E, Pelletier JG, Paz R, Paré D. 2005. Prefrontal control of the amygdala. J Neurosci 25: 7429-7437. doi:10.1523/JNEUROSCI.2314-05 .2005

Liu G, McNally RJ. 2017. Neutral mood induction during reconsolidation reduces accuracy, but not vividness and anxiety of emotional episodic memories. J Behav Ther Exp Psychiatry 54: 1-8. doi:10.1016/j.jbtep.2016 .05 .001

Liu X, Ramirez S, Pang PT, Puryear CB, Govindarajan A, Deisseroth K, Tonegawa S. 2012. Optogenetic stimulation of a hippocampal engram activates fear memory recall. Nature 484: 381-385. doi:10.1038/ nature11028

Lopez AJ, Kramar E, Matheos DP, White AO, Kwapis J, Vogel-Ciernia A, Sakata K, Espinoza M, Wood MA. 2016. Promoter-specific effects of DREADD modulation on hippocampal synaptic plasticity and memory formation. J Neurosci 36: 3588-3599. doi:10.1523/JNEUROSCI.3682-15 .2016
Lübke KT, Pause BM. 2014. Sex-hormone dependent perception of androstenone suggests its involvement in communicating competition and aggression. Physiol Behav 123: 136-141. doi:10.1016/j.physbeh .2013 .10 .016

Lux V, Atucha E, Kitsukawa T, Sauvage MM. 2016. Imaging a memory trace over half a life-time in the medial temporal lobe reveals a time-limited role of CA3 neurons in retrieval. Elife 5: e11862. doi:10.7554/eLife .11862

Mahler SV, Vazey EM, Beckley JT, Keistler CR, McGlinchey EM, Kaufling J, Wilson SP, Deisseroth K, Woodward JJ, Aston-Jones G. 2014. Designer receptors show role for ventral pallidum input to ventral tegmental area in cocaine seeking. Nat Neurosci 17: 577-585. doi:10.1038/nn.3664

Mangels JA, Gershberg FB, Shimamura AP, Knight RT. 1996. Impaired retrieval from remote memory in patients with frontal lobe damage. Neuropsychology 10: 32-41. doi:10.1037/0894-4105.10.1.32

Maren S, Phan K, Liberzon I. 2013. The contextual brain: implications for fear conditoning, extinction, and pschopathology. Nat Rev Neurosci 14: 417-426. doi:10.1038/nrn3492

Markowitsch H, Calabrese P, Liess J, Haupts M, Durwen H, Gehlen W. 1993. Retrograde amnesia after traumatic injury of the fronto-temporal cortex. J Neurol Neurosurg Psychiatry 56: 988-992. doi:10.1136/jnnp.56.9.988

Marr D. 1971. Simple memory: a theory for archicortex. Philos Trans $R$ Soc Lond B Biol Sci 262: 23-81. doi:10.1098/rstb.1971.0078

Mastrodonato A, Martinez R, Pavlova IP, LaGamma CT, Brachman RA, Robison AJ, Denny CA. 2018. Ventral CA3 activation mediates prophylactic ketamine efficacy against stress-induced depressive-like behavior. Biol Psychiatry 84: 846-856. doi:10.1016/j.biopsych.2018.02 .011

Maviel T, Durkin TP, Menzaghi F, Bontempi B. 2004. Sites of neocortical reorganization critical for remote spatial memory. Science 305: 96-99. doi:10.1126/science.1098180

Meeter M, Murre JMJ. 2004. Consolidation of long-term memory: evidence and alternatives. Psychol Bull 130: 843-857. doi:10.1037/0033-2909 .130 .6 .843

Milad MR, Quirk GJ, Pitman RK, Orr SP, Fischl B, Rauch SL. 2007. A role for the human dorsal anterior cingulate cortex in fear expression. Biol Psychiatry 62: 1191-1194. doi:10.1016/j.biopsych.2007.04.032

Mölle M, Yeshenko O, Marshall L, Sara SJ, Born J. 2006. Hippocampal sharp wave-ripples linked to slow loscillations in rat slow-wave sleep. J Neurophysiol 96: 62-70. doi:10.1152/jn.00014.2006

Morrison FG, Ressler KJ. 2014. From the neurobiology of extinction to improved clinical treatments. Depress Anxiety 31:279-290. doi:10.1002/ da. 22214

Moscovitch M, Rosenbaum RS, Gilboa A, Addis DR, Westmacott R, Grady C, McAndrews MP, Levine B, Black S, Winocur G, et al. 2005. Functional neuroanatomy of remote episodic, semantic and spatial memory: a unified account based on multiple trace theory. J Anat 207: 35-66. doi:10.1111/j.1469-7580.2005.00421.x

Murre J, Graham K, Hodges J. 2001. Semantic dementia: relevance to connectionist models of long-term memory. Brain 124: 647-675. doi:10 1093/brain/124.4.647

Nadel L, Moscovitch M. 1997. Memory consolidation, retrograde amnesia and the hippocampal complex. Curr Opin Neurobiol 7: 217-227. doi:10 .1016/S0959-4388(97)80010-4

Nadel L, Samsonovich A, Ryan L, Moscovitch M. 2000. Multiple trace theory of human memory: computational, neuroimaging, and neuropsychological results. Hippocampus 10: 352-368. doi:10.1002/ 1098-1063(2000)10:4<352::AID-HIPO2>3.0.CO;2-D

Nadel L, Winocur G, Ryan L, Moscovitch M. 2007. Systems consolidation and hippocampus: two views. Debates Neurosci 1: 55-66. doi:10.1007/ s11559-007-9003-9

Orsini CA, Maren S. 2012. Neural and cellular mechanisms of fear and extinction memory formation. Neurosci Biobehav Rev 36: 1773-1802. doi:10.1016/j.neubiorev.2011.12.014

Otchy TM, Wolff SBE, Rhee JY, Pehlevan C, Kawai R, Kempf A, Gobes SMH, Ölveczky BP. 2015. Acute off-target effects of neural circuit manipulations. Nature 528: 358-363. doi:10.1038/nature16442

Parfitt GM, Nguyen R, Bang JY, Aqrabawi AJ, Tran MM, Seo DK, Richards BA, Kim JC. 2017. Bidirectional control of anxiety-related behaviors in mice: role of inputs arising from the ventral hippocampus to the lateral septum and medial prefrontal cortex. Neuropsychopharmacology 42: 1715-1728. doi:10.1038/npp.2017.56

Parnaudeau S, O'Neill P-K, Bolkan SS, Ward RD, Abbas AI, Roth BL, Balsam PD, Gordon JA, Kellendonk C. 2013. Inhibition of mediodorsal thalamus disrupts thalamofrontal connectivity and cognition. Neuron 77: 1151-1162. doi:10.1016/j.neuron.2013.01.038

Pedraza LK, Sierra RO, Crestani AP, Quillfeldt JA, de Oliveira Alvares L. 2017. Sequential learning during contextual fear conditioning guides the rate of systems consolidation: implications for consolidation of multiple memory traces. Hippocampus 27: 518-528. doi:10.1002/hipo.22708 
Pei Y, Rogan SC, Yan F, Roth BL. 2008. Engineered GPCRs as tools to modulate signal transduction. Physiology 23: 313-321. doi:10.1152/ physiol.00025.2008

Piolino P, Giffard-Quillon G, Desgranges B, Chételat G, Baron J-C, Eustache F. 2004. Re-experiencing old memories via hippocampus: a PET study of autobiographical memory. Neuroimage 22: 1371-1383. doi:10.1016/j .neuroimage.2004.02.025

Plendl W, Wotjak CT. 2010. Dissociation of within- and between-session extinction of conditioned fear. J Neurosci 30: 4990-4998. doi:10.1523/ JNEUROSCI.6038-09.2010

Poulos AM, Mehta N, Lu B, Amir D, Livingston B, Santarelli A, Zhuravka I, Fanselow MS. 2016. Conditioning- and time-dependent increases in context fear and generalization. Learn Mem 23: 379-385. doi:10.1101/ $\operatorname{lm} .041400 .115$

Proust M. 1927. Le Temps Retrouve, 2nd ed. JCM, France.

Qin S, Piekema C, Petersson KM, Han B, Luo J, Fernández G. 2007. Probing the transformation of discontinuous associations into episodic memory: an event-related fMRI study. Neuroimage 38: 212-222. doi:10.1016/j .neuroimage.2007.07.020

Radulovic J, Kammermeier J, Spiess J. 1998. Relationship between fos production and classical fear conditioning: effects of novelty, latent inhibition, and unconditioned stimulus preexposure. J Neurosci 18: 7452-7461. doi:10.1523/JNEUROSCI.18-18-07452.1998

Rao-Ruiz P, Yu J, Kushner SA, Josselyn SA. 2019. Neuronal competition: microcircuit mechanisms define the sparsity of the engram. Curr Opin Neurobiol 54: 163-170. doi:10.1016/j.conb.2018.10.013

Rasmusson AM, Charney DS. 1997. Animal models of relevance to PTSD. Ann N Y Acad Sci 821: 332-351. doi:10.1111/j.1749-6632.1997 .tb48290.x

Redish AD, Touretzky DS. 1998. The role of the hippocampus in solving the Morris water maze. Neural Comput 10: 73-111. doi:10.1162/ 089976698300017908

Redondo RL, Kim J, Arons AL, Ramirez S, Liu X, Tonegawa S. 2014. Bidirectional switch of the valence associated with a hippocampal contextual memory engram. Nature 513: 426-430. doi:10.1038/ nature 13725

Reed J, Squire L. 1998. Retrograde amnesia for facts and events: findings from four new cases. J Neurosci 18: 3943-3954. doi:10.1523/JNEUROSCI .18-10-03943.1998

Reijmers LG, Perkins BL, Matsuo N, Mayford M. 2007. Localization of a stable neural correlate of associative memory. Science 317: 1230-1233. doi:10.1126/science.1143839

Rekkas PV, Constable RT. 2005. Evidence that autobiographic memory retrieval does not become independent of the hippocampus: an fMRI study contrasting very recent with remote events. J Cogn Neurosci 17: 1950-1961. doi:10.1162/089892905775008652

Rempel-Clower N, Zola S, Squire LR, Amaral DG. 1996. Three cases of enduring memory impairment after bilateral damage limited to the hippocampal formation. J Neurosci 16: 5233-5255. doi:10.1523/ JNEUROSCI.16-16-05233.1996

Ribot T. 1882. Diseases of the memory: an essay in the positive psychology. Appleton and Company, New York.

Richards M, Martin I. 1990. Eysenck's incubation of fear hypothesis: an experimental test. Behav Res Ther 28: 373-384. doi:10.1016/0005-7967 (90)90156-D

Rosenbaum RS, Winocur G, Moscovitch M. 2001. New views on old memories: re-evaluating the role of the hippocampal complex. Behav Brain Res 127: 183-197. doi:10.1016/S0166-4328(01)00363-1

Ross RS, Eichenbaum H. 2006. Dynamics of hippocampal and cortical activation during consolidation of a nonspatial memory. J Neurosci 26: 4852-4859. doi:10.1523/JNEUROSCI.0659-06.2006

Roth BL. 2016. DREADDs for neuroscientists. Neuron 89: 683-694. doi:10 .1016/j.neuron.2016.01.040

Roy DS, Park Y-G, Ogawa SK, Cho JH, Choi H, Kamensky L, Martin J, Chung $\mathrm{K}$, Tonegawa S. 2019. Brain-wide mapping of contextual fear memory engram ensembles supports the dispersed engram complex hypothesis. bioRxiv 668483. doi:10.1101/668483

Rubin DC, Feldman ME, Beckham JC. 2004. Reliving, emotions, and fragmentation in the autobiographical memories of veterans diagnosed with PTSD. Appl Cogn Psychol 18: 17-35. doi:10.1002/acp.950

Rubin DC, Boals A, Berntsen D. 2008. Memory in posttraumatic stress disorder: properties of voluntary and involuntary, traumatic and nontraumatic autobiographical memories in people with and without posttraumatic stress disorder symptoms. JExp Psychol Gen 137: 591-614. doi:10.1037/a0013165

Rubin DC, Dennis MF, Beckham JC. 2011. Autobiographical memory for stressful events: the role of autobiographical memory in posttraumatic stress disorder. Conscious Cogn 20: 840-856. doi:10.1016/j.concog.2011 .03 .015

Ryan TJ, Roy DS, Pignatelli M, Arons A, Tonegawa S. 2015. Engram cells retain memory under retrograde amnesia. Science 348: 1007-1013. doi:10.1126/science.aaa5542
Sahay A, Wilson DA, Hen R. 2011. Pattern separation: a common function for new neurons in hippocampus and olfactory bulb. Neuron 70: 582588. doi:10.1016/j.neuron.2011.05.012

Sano Y, Shobe JL, Zhou M, Huang S, Shuman T, Cai DJ, Golshani P, Kamata M, Silva AJ. 2014. CREB regulates memory allocation in the insular cortex. Curr Biol 24: 2833-2837. doi:10.1016/j.cub.2014.10.018

Schelach L, Nachson I. 2001. Memory of Auschwitz survivors. Appl Cogn Psychol 15: 119-132. doi:10.1002/1099-0720(200103/04)15:2<119:: AID-ACP692>3.0.CO;2-N

Schmidt B, Marrone DF, Markus EJ. 2012. Disambiguating the similar: the dentate gyrus and pattern separation. Behav Brain Res 226: 56-65.

Schmidt B, Duin AA, Redish AD. 2019. Disrupting the medial prefrontal cortex alters hippocampal sequences during deliberative decision making. J Neurophysiol 121: 1981-2000. doi:10.1152/jn.00793.2018

Scoville W, Milner B. 1957. Loss of recent memory after bilateral hippocampal lesions. I Neurol Neurosurg Psychiatry 20: 11-21. doi:10 .1136/jnnp.20.1.11

Semon R. 1921. The Mneme : 1859-1918. Allen \& Unwin, New York.

Shepherd GM. 2005. Perception without a thalamus: how does olfaction do it? Neuron 46: 166-168. doi:10.1016/j.neuron.2005.03.012

Shimizu E, Tang YP, Rampon C, Tsien JZ. 2000. NMDA receptor-dependent synaptic reinforcement as a crucial process for memory consolidation. Science 290: 1170-1174. doi:10.1126/science.290.5494.1170

Siegmund A, Wotjak CT. 2007. A mouse model of posttraumatic stress disorder that distinguishes between conditioned and sensitised fear. $J$ Psychiatr Res 41: 848-860. doi:10.1016/j.jpsychires.2006.07.017

Sierra-Mercado D, Padilla-Coreano N, Quirk GJ. 2011. Dissociable roles of prelimbic and infralimbic cortices, ventral hippocampus, and basolateral amygdala in the expression and extinction of conditioned fear. Neuropsychopharmacology 36: 529-538. doi:10.1038/npp.2010.184

Silva BA, Burns AM, Gräff J. 2018. A cFos activation map of remote fear memory attenuation. Psychopharmacology (Berl) 236: 369-381. doi:10 $.1007 / \mathrm{s} 00213-018-5000-\mathrm{y}$

Singewald N. 2007. Altered brain activity processing in high-anxiety rodents revealed by challenge paradigms and functional mapping. Neurosci Biobehav Rev 31: 18-40. doi:10.1016/j.neubiorev.2006.02.003

Skaggs WE, McNaughton BL. 1996. Replay of neuronal firing sequences in rat hippocampus during sleep following spatial experience. Science 271: 1870-1873. doi:10.1126/science.271.5257.1870

Squire LR. 1992. Memory and the hippocampus: a synthesis from findings with rats, monkeys, and humans. Psychol Rev 99: 195-231. doi:10.1037/ 0033-295X.99.2.195

Squire LR, Bayley PJ. 2007. The neuroscience of remote memory. Curr Opin Neurobiol 17: 185-196. doi:10.1016/j.conb.2007.02.006

Squire LR, Wixted JT. 2011. The cognitive neuroscience of human memory since H.M. Annu Rev Neurosci 34: 259-288. doi:10.1146/ annurev-neuro-061010-113720

Squire LR, Genzel L, Wixted JT, Morris RG. 2015. Memory consolidation. Cold Spring Harb Perspect Biol 7: a021766. doi:10.1101/cshperspect .a021766

Strekalova T, Zörner B, Zacher C, Sadovska G, Herdegen T, Gass P. 2003. Memory retrieval after contextual fear conditioning induces c-Fos and JunB expression in CA1 hippocampus. Genes Brain Behav 2: 3-10. doi:10 .1034/j.1601-183X.2003.00001.x

Sutherland RJ, O'Brien J, Lehmann H. 2008. Absence of systems consolidation of fear memories after dorsal, ventral, or complete hippocampal damage. Hippocampus 18: 710-718. doi:10.1002/hipo .20431

Suzuki W, Naya Y. 2011. Two routes for remembering the past. Cell 147: 493-495. doi:10.1016/j.cell.2011.10.005

Sweeney P, Yang Y. 2015. An excitatory ventral hippocampus to lateral septum circuit that suppresses feeding. Nat Commun 6: 10188. doi:10 .1038/ncomms10188

Takahashi T, Nakamura M, Sasabayashi D, Komori Y, Higuchi Y, Nishikawa Y, Nishiyama S, Itoh H, Masaoka Y, Suzuki M. 2018. Olfactory deficits in individuals at risk for psychosis and patients with schizophrenia: relationship with socio-cognitive functions and symptom severity. Eur Arch Psychiatry Clin Neurosci 268: 689-698. doi:10.1007/ s00406-017-0845-3

Tayler KK, Tanaka KZ, Reijmers LG, Wiltgen BJ. 2013. Reactivation of neural ensembles during the retrieval of recent and remote memory. Curr Biol 23: 99-106. doi:10.1016/j.cub.2012.11.019

Teixeira CM, Pomedli SR, Maei HR, Kee N, Frankland PW. 2006. Involvement of the anterior cingulate cortex in the expression of remote spatial memory. J Neurosci 26: 7555-7564. doi:10.1523/JNEUROSCI $.1068-06.2006$

Toffolo MBJ, Smeets MAM, van den Hout MA. 2012. Proust revisited: odours as triggers of aversive memories. Cogn Emot 26: 83-92. doi:10.1080/ 02699931.2011 .555475

Tonegawa S, Liu X, Ramirez S, Redondo R. 2015. Memory engram cells have come of age. Neuron 87: 918-931. doi:10.1016/j.neuron.2015.08.002 
Trouche S, Perestenko PV, van de Ven GM, Bratley CT, McNamara CG, Campo-Urriza N, Black SL, Reijmers LG, Dupret D. 2016. Recoding a cocaine-place memory engram to a neutral engram in the hippocampus. Nat Neurosci 19: 564-567. doi:10.1038/nn.4250

Tse D, Langston R, Kakeyama M, Bethus I, Spooner P, Wood E, Witter M, Morris R. 2007. Schemas and memory consolidation. Science 316: 7682. doi:10.1126/science. 1135935

Tulving E. 2002. Episodic memory: from mind to brain. Annu Rev Psychol 53: 1-25. doi:10.1146/annurev.psych.53.100901.135114

Vermetten E, Bremner JD. 2003. Olfaction as a traumatic reminder in posttraumatic stress disorder: case reports and review. J Clin Psychiatry 64: 202-207. doi:10.4088/JCP.v64n0214

Vetere G, Tran LM, Moberg S, Steadman PE, Restivo L, Morrison FG, Ressler KJ, Josselyn SA, Frankland PW. 2019. Memory formation in the absence of experience. Nat Neurosci 22: 933-940. doi:10.1038/ s41593-019-0389-0

Vidal-Gonzalez I, Vidal-Gonzalez B, Rauch SL, Quirk GJ. 2006. Microstimulation reveals opposing influences of prelimbic and infralimbic cortex on the expression of conditioned fear. Learn Mem 13: 728-733. doi:10.1101/lm.306106

Wagenaar WA, Groeneweg J. 1990. The memory of concentration camp survivors. Appl Cogn Psychol 4: 77-87. doi:10.1002/acp .2350040202

Wang J, Chen Y, Carlson S, Li L, Hu X, Ma Y. 2012. Interactive effects of morphine and scopolamine, MK-801, propanolol on spatial working memory in rhesus monkeys. Neurosci Lett 523: 119-124. doi:10.1016/j .neulet.2012.06.056

Weeden CSS, Hu NJ, Ho LUN, Kesner RP. 2014. The role of the ventral dentate gyrus in olfactory pattern separation. Hippocampus 24: 553-559. doi:10.1002/hipo. 22248
Wiltgen BJ, Silva AJ. 2007. Memory for context becomes less specific with time. Learn Mem 14: 313-317. doi:10.1101/lm.430907

Wiltgen BJ, Brown RAM, Talton LE, Silva AJ. 2004. New circuits for old memories: the role of the neocortex in consolidation. Neuron 44: 101108. doi:10.1016/j.neuron.2004.09.015

Wiltgen BJ, Zhou M, Cai Y, Balaji J, Karlsson MG, Parivash SN, Li W, Silva AJ. 2010. The hippocampus plays a selective role in the retrieval of detailed contextual memories. Curr Biol 20: 1336-1344. doi:10.1016/j.cub.2010 .06 .068

Yassa MA, Reagh ZM. 2013. Competitive trace theory: a role for the hippocampus in contextual interference during retrieval. Front Behav Neurosci 7: 107. doi:10.3389/fnbeh.2013.00107

Zelikowsky M, Pham DL, Fanselow MS. 2012. Temporal factors control hippocampal contributions to fear renewal after extinction. Hippocampus 22: 1096-1106. doi:10.1002/hipo.20954

Zhu H, Roth BL. 2015. DREADD: a chemogenetic GPCR signaling platform. Int J Neuropsychopharmacol 18: pyu007. doi:10.1093/ijnp/pyu007

Zhu H, Pleil KE, Urban DJ, Moy SS, Kash TL, Roth BL. 2014. Chemogenetic inactivation of ventral hippocampal glutamatergic neurons disrupts consolidation of contextual fear memory. Neuropsychopharmacology 39: 1880-1892. doi:10.1038/npp.2014.35

Zola-Morgan S, Squire LR. 1986. Memory impairment in monkeys following lesions limited to the hippocampus. Behav Neurosci 100: 155-160. doi:10.1037/0735-7044.100.2.155

Zucco GM, Aiello L, Turuani L, Koster E. 2012. Odor-evoked autobiographical memories: age and gender differences along the life span. Chem Senses 37: 179-189. doi:10.1093/chemse/bjr089

Received August 21, 2019; accepted in revised form December 31, 2019. 


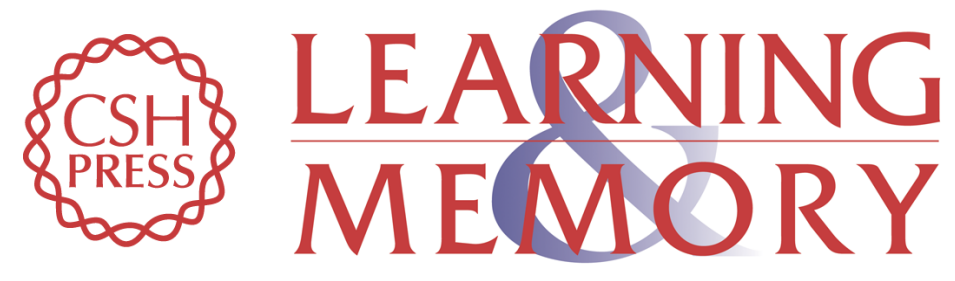

\section{Odor modulates the temporal dynamics of fear memory consolidation}

Stephanie L. Grella, Amanda H. Fortin, Olivia McKissick, et al.

Learn. Mem. 2020, 27:

Access the most recent version at doi:10.1101/Im.050690.119

References This article cites 156 articles, 38 of which can be accessed free at: http://learnmem.cshlp.org/content/27/4/150.full.html\#ref-list-1

Creative This article, published in Learning \& Memory, is available under a Creative Commons Commons License (Attribution-NonCommercial 4.0 International), as described at License http://creativecommons.org/licenses/by-nc/4.0/.

Email Alerting Receive free email alerts when new articles cite this article - sign up in the box at the Service top right corner of the article or click here. 